\title{
Early Age Deformation and Resultant Induced Stress in Expansive High Strength Concrete
}

\author{
Hidetoshi Ito $^{1}$, Ippei Maruyama ${ }^{2}$, Makoto Tanimura $^{3}$ and Ryoichi Sato ${ }^{4}$
}

Received 2 November 2003, accepted 16 February 2004

\begin{abstract}
Expansive additive is well known to be effective in compensating early-age shrinkage and the resultant induced stress in reinforced high-strength concrete (HSC) members. On the other hand, there have been few studies on numerical analysis methods for evaluating such early-age induced stress, which are vital to verify the risk of cracking. The present study formulates a 3-dimensional finite element method as well as a practical calculation method based on the beam theory, both of which consider the principle of superposition and linear stress-strain relationship of creep, in order to evaluate the early-age shrinkage/expansion-induced stress in reinforced members. The applicability of the proposed methods is evaluated by comparing computed values with experimental values on shrinkage/expansion-induced stress in $\mathrm{RC}$ beam specimens composed of various HSCs, using expansive additive and/or shrinkage reducing chemical agent and/or low-heat Portland cement. The results demonstrate that the proposed finite element method can accurately simulate induced stress in the reinforced concrete beams, even when expansive additive is used, and this indicates that the linear stress-strain relationship may be valid for expansive high strength concrete. Furthermore, there is a good agreement between the finite element method and a practical calculation method based on the beam theory, even in the case of $\mathrm{RC}$ beams with stirrups that cause a three-dimensional restraint condition in concrete.
\end{abstract}

\section{Introduction}

The development of superplasticizer and the widespread use of supplementary mineral powders such as silica fume and granulated blast-furnace slag have enabled the provision of high-strength and/or high-flowability concrete. High-strength concrete (HSC) has been widely studied over the last decade and has been increasingly applied in order to enhance the durability and structural performance of concrete structures. However, such low water-to-binder ratio concretes have already been known to shrink significantly at early ages, which is likely to be caused mainly by autogenous shrinkage (self-desiccation shrinkage), and frequently exhibit increased sensitivity to early-age cracking (Paillere et al. 1989; Tazawa et al. 1992a; Schrage et al. 1992; Tazawa et al. 1994). In addition, some authors have experimentally demonstrated that autogenous shrinkage has a bad influence on the structural performance of reinforced

\footnotetext{
${ }^{1}$ Associate Professor, Department of Civil and Architectural Engineering, Hiroshima Institute of Technology, Japan

${ }^{2}$ Research Associate, Department of Social and Environmental Engineering, Hiroshima University, Japan

E-mail: ippei@hiroshima-u.ac.jp

${ }^{3}$ Research Scientist, Research \& Development Center, Taiheiyo Cement Corporation, Japan

${ }^{4}$ Professor, Department of Social and Environmental Engineering, Hiroshima University, Japan
}

concrete (RC) members under service load conditions (Tanimura et al. 2001a; Tanimura et al. 2002a; Sato et al. 2003), which results in degradation of the durability of concrete structures.

Control of cracking in RC members is always a matter of concern because the durability of concrete structures often declines with crack formation. HSC is expected to yield more durable structural members, and more severe control of cracking for HSC compared to traditional concrete is essential. Thus, the establishment of a technique for minimizing autogenous shrinkage in HSC has been an important task.

Recently, experimental investigations on controlling autogenous shrinkage have been carried out comprehensively from the material point of view (JCI 1999a). These studies revealed that expansive additive (Tazawa et al. 1992b; Hori et al. 1998; Tanimura et al. 2000; Schwartzentruber et al. 2002), shrinkage-reducing chemical agent (Tazawa et al. 1992b; Weiss et al. 1999; Tanimura et al. 2000; Holt et al. 2000; Bentz et al. 2001; Berke et al. 2003), as well as Portland cement containing higher $\mathrm{C}_{2} \mathrm{~S}$ content and lower $\mathrm{C}_{3} \mathrm{~A}$ or $\mathrm{C}_{4} \mathrm{AF}$ content (Tazawa et al. 1995) are effective for reducing autogenous shrinkage. Additionally, the effect of the combination of the above-mentioned materials on reducing autogenous shrinkage has been investigated, and HSCs with lower risk of early-age cracking have been developed (Ogawa et al. 1995; Chikamatsu et al. 1997; Sato et al. 1999a; Kameta et al. 2000; Tanimura et al. 2000; Hori et al. 2001; Tanimura et al. 2001b; Tanimura et al. 2002b). Very recently, techniques called internal water curing of concrete, which enable counteracting 
self-desiccation by partly replacing normal weight aggregate with pre-saturated lightweight aggregate or adding super-adsorbent polymer particles as concrete admixture, have been reported (Bentur et al. 2001; Jensen et al. 2001; Jensen et al. 2002).

However, only a few studies to evaluate induced stress in RC members using shrinkage-reducing materials have been performed, and there have been few reports on numerical analysis methods for calculating induced stress due to early-age deformation (Tsutsui et al. 1996; Sato et al. 1997; Sato et al. 1999b), although the establishment of such methods is vital to verify the risk of cracking, as well as the serviceability performance of RC members (JSCE 2002; Sato et al. 2003). There have been particularly few analytical investigations on early-age induced stress in HSC containing expansive additive. Pointing this area, Sato et al. (Sato et al. 1999a) carried out two-dimensional finite element analysis based on the effective modulus method considering the principle of superposition and the age at application of load on creep in order to evaluate early-age shrinkage/expansion-induced stress in RC beams. A comparison of the computed values with the measured values indicated the necessity of adopting stricter creep analysis methods and actual creep coefficients.

Against the above-described background, the present study aims to evaluate the effect of shrinkage-reducing materials on control of autogenous shrinkage induced stress in RC members, and also to propose a relevant numerical analysis method based on a step-by-step procedure (Neville et al. 1983) considering the principle of superposition and the age at application of load on creep for calculating early-age shrinkage/expansion-induced stress. For this purpose, RC beam specimens consisting of various HSCs with a low water-cement ratio, using expansive additive and/or shrinkage reducing chemical agent and/or $\mathrm{C}_{2} \mathrm{~S}$-rich Portland cement, and subjected to early-age induced stresses, were experimentally evaluated. At the same time, Young's modulus and creep coefficients were measured and modeled based on CEB-FIP Model Code MC90 in order to apply numerical analysis. The applicability of the proposed method was demonstrated by comparison with the experimental values.

On the other hand, Tsuji (Tsuji 1980) suggested a convenient method for estimating the strain/stress of reinforcing bars in RC members made of expansive concrete, based on the hypothesis that the quantity of work per unit volume by expansion is constant. The applicability of this hypothesis has been shown for normal-strength expansive concretes, which have marked nonlinearity behavior, whereas verification for HSC with stiffer structure has been insufficient. This study, therefore, also draws a comparison between the proposed method and the hypothesis suggested by Tsuji, in the HSC field.

\section{Analysis method}

\subsection{Finite element analysis 2.1.1 Basic equation for superposition principle of creep strain}

The sum of elastic and creep strain in concrete is proportional to a sustained load under ordinary service stress level. The strain by volume change is superposed on the stress-induced strain.

Hence, a uniaxial strain-stress relationship of concrete with deformation and stress history can be expressed as:

$$
\varepsilon_{x}\left(t_{i+1 / 2}\right)=\sum_{j=1}^{i}\left[\left(\Delta \sigma_{x, c}\right)_{j} J\left(t_{i+1 / 2}, t_{j}\right)\right]+\varepsilon_{x, \Delta T, a s, d s}\left(t_{i+1 / 2}, t_{1 / 2}\right)(1)
$$

where $t_{i+1 / 2}, t_{i}$ : end and middle of $i$-th time interval, $\varepsilon_{x}\left(t_{i+1 / 2}\right)$ : strain in the $\mathrm{x}$-axis at the end of $i$-th time interval, $\left(\Delta \sigma_{x, c}\right)_{j}$ : incremental stress in the $\mathrm{x}$-axis at $j$-th time interval, $E_{c}\left(t_{j}\right)$ : Young's modulus at $t_{j}$ in temperature adjusted concrete age, $E_{c, 28}$ : Young's modulus at 28 days in temperature adjusted concrete age, $\phi\left(t_{i+1 / 2}, t_{j}\right)$ : creep coefficient at $t_{i+1 / 2}$ caused by a constant load applied at $t_{j}, \quad \varepsilon_{x, \Delta T, a s, d s}\left(t_{i+1 / 2}, t_{1 / 2}\right)$ : difference of free strain in the $\mathrm{x}$-axis due to temperature change and shrinkage or expansion of concrete from $t_{1 / 2}$ to $t_{i+1 / 2}$, and $J\left(t_{i+1 / 2}, t_{j}\right)=\frac{1}{E_{c}\left(t_{j}\right)}+\frac{\phi\left(t_{i+1 / 2}, t_{j}\right)}{E_{c}, 28}$ : Compliance function.

Temperature adjusted concrete age is calculated by:

$$
t=\sum_{i=1}^{n} \Delta t_{i} \exp \left[13.65-\frac{4000}{273+T\left(\Delta t_{i}\right) / T_{0}}\right]
$$

where, $t:$ temperature adjusted concrete age, $\Delta t_{i}$ : number of days where a temperature $\mathrm{T}\left({ }^{\circ} \mathrm{C}\right)$ prevails, $T_{0}=1^{\circ} \mathrm{C}$

The difference of strain at $i$-th time interval and $(i-1)$-th time interval introduced by Eq. 1 is given by:

$$
\begin{gathered}
\left(\Delta \varepsilon_{x, c}\right)_{i}=\varepsilon_{x}\left(t_{i+1 / 2}\right)-\varepsilon_{x}\left(t_{(i-1)+1 / 2}\right) \\
=\left(\Delta \sigma_{x, c}\right)_{i} J\left(t_{i+1 / 2}, t_{i}\right)+\sum_{j=1}^{i-1}\left[\left(\Delta \sigma_{x, c}\right)_{j} \frac{\Delta \phi\left(t_{i}, t_{j}\right)}{E_{c}, 28}\right]+\left(\Delta \varepsilon_{x, \Delta T, a s, d s}\right)_{i} \\
\Delta \phi\left(t_{i}, t_{j}\right)=\phi\left(t_{i+1 / 2}, t_{j}\right)-\phi\left(t_{(i-1)+1 / 2}, t_{j}\right)
\end{gathered}
$$

where, $\left(\Delta \varepsilon_{x, c}\right)_{i}$ : incremental strain in the $\mathrm{x}$-axis at $i$-th time interval, $\left(\Delta \sigma_{x, c}\right)_{i}$ : incremental stress in the $\mathrm{x}$-axis at $i$-th time interval, $\left(\Delta \varepsilon_{x, \Delta T, a s, d s}\right):$ incremental free strain due to temperature change and shrinkage or expansion of concrete in the $\mathrm{x}$-axis at $i$-th time interval.

According to Eq. 3, when the stress and the strain until $(i-1)$-th interval are known and an incremental strain $\left(\Delta \varepsilon_{x, c}\right)_{i}$ at $i$-th interval is given, the incremental stress $\left(\Delta \sigma_{x, c}\right)_{i}$ at $i$-th interval is obtained as: 


$$
\begin{aligned}
& \left(\Delta \sigma_{x, c}\right)_{i}=\frac{E_{c}\left(t_{i}\right)}{1+\frac{E_{c}\left(t_{i}\right)}{E_{c}, 28} \phi\left(t_{i+1 / 2}, t_{i}\right)} \\
& \cdot\left\{\left(\Delta \varepsilon_{x, c}\right)_{i}-\sum_{j=1}^{i-1}\left[\frac{\left(\Delta \sigma_{x, c}\right)_{j}}{E_{c}, 28}\left(\Delta \phi\left(t_{i}, t_{j}\right)\right)\right]-\left(\Delta \varepsilon_{x, \Delta T, a s, d s}\right)_{i}\right\}
\end{aligned}
$$

Consequently the stress at $i$-th interval $\sigma_{x, c}\left(t_{i}\right)$ is calculated by:

$$
\sigma_{x, c}\left(t_{i}\right)=\sigma_{x, c}\left(t_{i-1}\right)+\left(\Delta \sigma_{x, c}\right)_{i}
$$

Based on the superposition principle of strain, Eq. 4 leads to the following 3-dimensional expression assuming isotropic property:

$$
\begin{aligned}
& \left\{\Delta \boldsymbol{\sigma}_{c}\right\}_{i} \\
& =\left[\boldsymbol{D}_{\boldsymbol{c}}\right]_{i}\left[\left\{\Delta \boldsymbol{\varepsilon}_{c}\right\}_{i}-\sum_{j=1}^{i-1}\left[\frac{\left(\Delta \boldsymbol{\sigma}_{\boldsymbol{c}}\right)_{j}}{\left[\boldsymbol{D}_{c, 28}\right]}\left(\Delta \phi\left(t_{i}, t_{j}\right)\right)\right]-\left\{\Delta \boldsymbol{\varepsilon}_{\Delta T, a s, d s}\right\}_{i}\right]
\end{aligned}
$$

where, $\left\{\Delta \sigma_{c}\right\}_{i}$ : incremental stress vector at $i$-th interval, $\left\{\Delta \varepsilon_{c}\right\}_{i}:$ incremental strain vector at $i$-th interval, $\left\{\Delta \varepsilon_{\Delta T, a s, d s}\right\}_{i}$ : incremental strain vector due to temperature change and shrinkage or expansion of concrete, $\left[\boldsymbol{D}_{\boldsymbol{c}}\right]_{i}$ : stress-strain matrix of concrete at $i$-th interval, $\left[\boldsymbol{D}_{c, 28}\right]$ : stiffness matrix of concrete at 28 days in temperature adjusted concrete age.

A schematic diagram of the proposed equation is shown in Fig. 1.

\subsubsection{Formulation of incremental finite element equation}

Based on the principle of virtual work, the following equation is obtained:

$$
\{\boldsymbol{\Delta P}\}^{T}\{\delta \Delta \boldsymbol{v}\}=\int_{V}\{\delta \Delta \boldsymbol{\varepsilon}\}^{T}\{\boldsymbol{\Delta} \boldsymbol{\sigma}\} d V
$$

where, $\{\boldsymbol{\Delta P}\}$ : load vector, $\{\boldsymbol{\delta} \Delta \boldsymbol{v}\}$ : virtual displacement vector, $\{\boldsymbol{\sigma}\}$ : stress vector according to load $\{\boldsymbol{\Delta P}\}$, $\{\delta \Delta \varepsilon\}$ : virtual strain vector by virtual displacement.

Displacement and strain have a following relationship:

$$
\begin{aligned}
& \{\delta \Delta \varepsilon\}=[B]\{\delta \Delta \boldsymbol{v}\} \\
& \left\{\Delta \varepsilon_{c}\right\}_{i}=[B]\left\{\Delta v_{c}\right\}_{i}
\end{aligned}
$$

where, $\left\{\boldsymbol{\Delta} \boldsymbol{v}_{\boldsymbol{c}}\right\}_{i}$ : displacement at $i$-th interval, $[\boldsymbol{B}]$ : strain-displacement matrix derived from the assumption of isoparametric 8-node, 6-hexaheron element with one dimensional shape function.

Substituting Eq. 7 into Eqs. 6, 8, and 9 results in:

$$
\begin{aligned}
& \{\delta \boldsymbol{\Delta} \boldsymbol{v}\}^{T}\{\boldsymbol{\Delta P}\}=\int_{V}([\boldsymbol{B}]\{\delta \boldsymbol{\Delta} \boldsymbol{v}\})^{T}\left[\boldsymbol{D}_{\boldsymbol{c}}\right]_{i} \\
& \left\{[B]\left\{\boldsymbol{\Delta} \boldsymbol{v}_{\boldsymbol{c}}\right\}_{i}-\sum_{j=1}^{i-1}\left[\frac{\left\{\boldsymbol{\Delta} \boldsymbol{\sigma}_{\boldsymbol{c}}\right\}_{j}}{\left[\boldsymbol{D}_{c, 28}\right]} \Delta \phi_{i, j}\right]-\left\{\boldsymbol{\Delta} \boldsymbol{\varepsilon}_{\boldsymbol{\Delta} \boldsymbol{T}, \boldsymbol{a s}, \boldsymbol{d s}}\right\}_{i}\right\} d V
\end{aligned}
$$

The creep, shrinkage and temperature parts in the right side of Eq. 10 can be expressed as equivalent nodal force. Hence the following equation is obtained:

$$
\begin{aligned}
& \{\boldsymbol{\Delta P}\}+\{\boldsymbol{\Delta} \boldsymbol{f}\}=\int_{V}[\boldsymbol{B}]^{T}\left[\boldsymbol{D}_{\boldsymbol{c}}\right]_{i}[\boldsymbol{B}] d V\left\{\boldsymbol{\Delta} \boldsymbol{v}_{\boldsymbol{c}}\right\}_{i} \\
& \{\boldsymbol{\Delta} \boldsymbol{f}\} \\
& =\int_{V}[\boldsymbol{B}]^{T}\left[\boldsymbol{D}_{\boldsymbol{c}}\right]_{i} \times\left\{\sum_{j=1}^{i-1}\left[\frac{\left\{\boldsymbol{\Delta} \boldsymbol{\sigma}_{\boldsymbol{c}}\right\}_{j}}{\left[\boldsymbol{D}_{\boldsymbol{c}, 28}\right]} \Delta \phi_{i, j}\right]+\left\{\boldsymbol{\Delta} \boldsymbol{\varepsilon}_{\boldsymbol{\Delta T}, \boldsymbol{a s}, d s}\right\}_{i}\right\} d V
\end{aligned}
$$

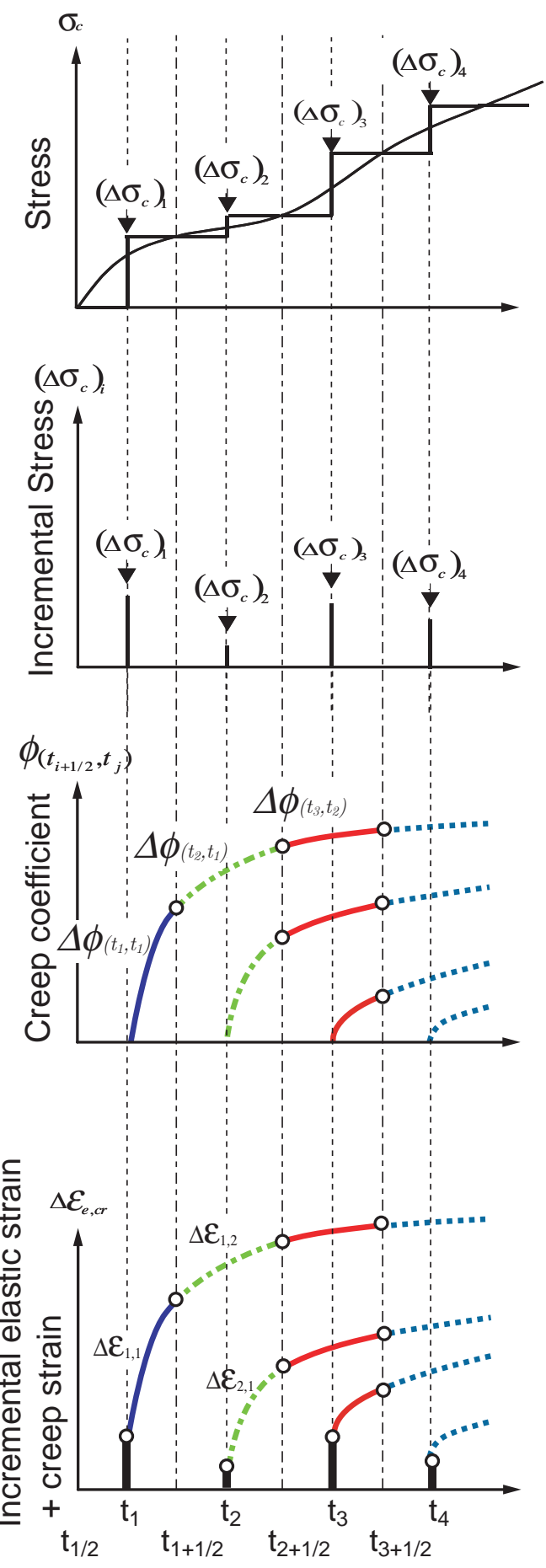

Fig. 1 Schematic diagram of incremental approach in proposed FE analysis. 
where, $\{\boldsymbol{\Delta} \boldsymbol{f}\}$ : equivalent nodal force vector of creep, shrinkage, and temperature strain.

With local stiffness matrix $\left[\boldsymbol{K}_{e}\right]$, Eq. 11 is expressed as:

$$
\{\boldsymbol{\Delta P}\}+\{\boldsymbol{\Delta} \boldsymbol{f}\}=\left[\boldsymbol{K}_{e}\right]\left\{\boldsymbol{\Delta} \boldsymbol{v}_{c}\right\}_{i}
$$

where, $\left[\boldsymbol{K}_{e}\right]=\int_{V}[\boldsymbol{B}]^{T}\left[\boldsymbol{D}_{c}\right]_{i}[\boldsymbol{B}] d V$ : local stiffness matrix.

The global stiffness matrix is constructed for the finite element (FE) method from local stiffness matrices according to the assembly principle, and nodal force and nodal displacement are obtained by solving the following simultaneous linear equation:

$$
\{\boldsymbol{\Delta} \boldsymbol{F}\}+\left\{\boldsymbol{\Delta} \boldsymbol{F}^{\prime}\right\}=[\boldsymbol{K}]\left\{\boldsymbol{\Delta} \boldsymbol{V}_{c}\right\}_{i}
$$

where, $\{\boldsymbol{\Delta} \boldsymbol{F}\}$ : global incremental load vector, $\left\{\boldsymbol{\Delta} \boldsymbol{F}^{\prime}\right\}$ : global incremental equivalent nodal force vector of creep, shrinkage, and temperature strain, $[\boldsymbol{K}]$ : global stiffness matrix, $\left\{\boldsymbol{\Delta} \boldsymbol{V}_{\boldsymbol{c}}\right\}_{i}$ : global incremental displacement vector.

\subsection{Beam theory}

In this section, a model based on the beam theory is proposed as a practical calculation method for stress analysis in a beam specimen. This proposed model deals with a beam that has two different depths of reinforcing bars. The basic concept for creep strain is the same as that of the FE analysis mentioned in section 2.1 above.

Eq. 3 can be expressed with the following compliance function:

$$
\begin{aligned}
\left(\Delta \varepsilon_{c}\right)_{i}= & \left(\Delta \sigma_{c}\right)_{i} J\left(t_{i+1 / 2}, t_{i}\right) \\
& +\sum_{j=1}^{i-1}\left[\left(\Delta \sigma_{c}\right)_{j} \Delta J\left(t_{i}, t_{j}\right)\right]+\left(\Delta \varepsilon_{\Delta T, a s, d s}\right)_{i}
\end{aligned}
$$

where, $\Delta J\left(t_{i}, t_{j}\right)=\frac{\phi\left(t_{i+1 / 2}, t_{j}\right)-\phi\left(t_{(i-1)+1 / 2}, t_{j}\right)}{E_{c}, 28}:$ differential of compliance function.

The concrete strain at the upper (compressive side) and lower (tensile side) reinforcing bars is obtained by the following equations:

$$
\begin{aligned}
& \Delta \varepsilon_{c c, i}=\Delta \sigma_{c c, i} J\left(t_{i+1 / 2}, t_{i}\right)+\sum_{j=1}^{i-1} \Delta \sigma_{c c, j} \Delta J\left(t_{i}, t_{j}\right)+\Delta \varepsilon_{s h, i} \\
& \Delta \varepsilon_{c t, i}=\Delta \sigma_{c t, i} J\left(t_{i+1 / 2}, t_{i}\right)+\sum_{j=1}^{i-1} \Delta \sigma_{c t, j} \Delta J\left(t_{i}, t_{j}\right)+\Delta \varepsilon_{s h, i}
\end{aligned}
$$

where, $t_{i+1 / 2}, t_{i}$ : end and middle of $i$-th time interval, $\Delta \varepsilon_{c c, i}$ :incremental strain of concrete at the same depth of compressive reinforcing bar at $i$-th time interval, $\Delta \varepsilon_{c t, i}$ : incremental strain of concrete at the same depth of tensile reinforcing bar at $i$-th time interval, $\Delta \sigma_{c c, i}$ : incremental stress of concrete at the same depth of compressive reinforcing bar at $i$-th time interval, $\Delta \sigma_{c t, i}$ : incremental stress of concrete at the same depth of tensile reinforcing bar at $i$-th time interval, $\Delta \varepsilon_{s h, i}$ i incremental free strain of concrete at $i$-th time interval.

The incremental stress of concrete is obtained by the force in reinforcing bars with the assumption of linear strain distribution:

$$
\begin{aligned}
& \left\{\begin{array}{l}
\alpha_{c c}=\frac{A_{s c} E_{s}}{A_{c}}\left(1+\frac{\left(d^{\prime}-C_{g}\right)^{2}}{I_{c} / A_{c}}\right) \\
\alpha_{t t}=\frac{A_{s t} E_{s}}{A_{c}}\left(1+\frac{\left(d-C_{g}\right)^{2}}{I_{c} / A_{c}}\right) \\
\alpha_{t c}=\frac{A_{s t} E_{s}}{A_{c}}\left(1+\frac{\left(d-C_{g}\right)\left(d^{\prime}-C_{g}\right)}{I_{c} / A_{c}}\right) \\
\alpha_{c t}=\frac{A_{s c} E_{s}}{A_{c}}\left(1+\frac{\left(d-C_{g}\right)\left(d^{\prime}-C_{g}\right)}{I_{c} / A_{c}}\right)
\end{array}\right. \\
& \Delta \sigma_{c c, i}=-\alpha_{c c} \Delta \varepsilon_{s c, i}-\alpha_{t c} \Delta \varepsilon_{s t, i} \\
& \Delta \sigma_{c t, i}=-\alpha_{c t} \Delta \varepsilon_{s c, i}-\alpha_{t t} \Delta \varepsilon_{s t, i}
\end{aligned}
$$

where, $d, d^{\prime}$ : distance from extreme top fiber to centroid of tension and compression reinforcement, $A_{c}$ : Cross sectional area of concrete in section of beam, $A_{s c}$ : Cross sectional area of compressive reinforcing bar in section, $A_{s t}$ : Cross sectional area of tensile reinforcing bar in section, $\Delta \varepsilon_{s c, i}$ : incremental strain in compressive reinforcing bar at $i$-th interval, $\Delta \varepsilon_{s t, i}$ : incremental strain in tensile reinforcing bar at $i$-th interval, $C_{g}$ : centroid of section, $I_{c}$ : geometrical moment of inertia.

The schematic diagram of self-induced stress in beam theory is shown in Fig. 2.

On the other hand, the conformity principle of strain is given by:

$$
\Delta \varepsilon_{c c, i}=\Delta \varepsilon_{s c, i}, \quad \Delta \varepsilon_{c t, i}=\Delta \varepsilon_{s t, i}
$$

Hence, combining Eqs. 16, 17, 18, and 19 results in the following equation with matrix form:

$$
\begin{gathered}
{\left[\begin{array}{cc}
1+\alpha_{c c} J\left(t_{i+1 / 2}, t_{i}\right) & \alpha_{t c} J\left(t_{i+1 / 2}, t_{i}\right) \\
\alpha_{c t} J\left(t_{i+1 / 2}, t_{i}\right) & 1+\alpha_{t t} J\left(t_{i+1 / 2}, t_{i}\right)
\end{array}\right]\left\{\begin{array}{c}
\Delta \varepsilon_{s c, i} \\
\Delta \varepsilon_{s t, i}
\end{array}\right\}} \\
=\sum_{j=1}^{i-1}\left\{\begin{array}{l}
\Delta \sigma_{c c, j} \Delta J\left(t_{i}, t_{j}\right) \\
\Delta \sigma_{c t, j} \Delta J\left(t_{i}, t_{j}\right)
\end{array}\right\}+\left\{\begin{array}{l}
\Delta \varepsilon_{s h, i}, \\
\Delta \varepsilon_{s h, i}
\end{array}\right\}
\end{gathered}
$$

According to Eq. 21, the incremental stress of concrete and reinforcing bars at the $i$-th interval is obtained

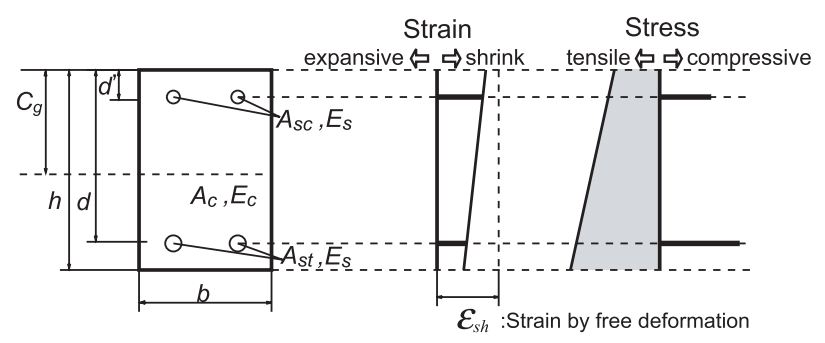

Fig. 2 Schematic diagram of self-induced stress in beam theory. 
when the histories of the incremental stress, the incremental deformation until ( $i-1)$-th interval, and the incremental deformation at $i$-th interval are given.

\section{Experiments and materials}

\subsection{Materials and mixture proportions}

Table 1 lists the materials used for the experiments and Table 2 lists the mixture as well as air content, slump flow, and temperature just after mixing.

$\mathrm{NC} 1, \mathrm{NC} 2, \mathrm{NC} 3$ and $\mathrm{NC} 4$ designate reference high-strength and highly flowable concrete made using ordinary Portland cement. These four types of concrete differ by their aggregate quality and water-to-cement ratio. NE-CSA represents concrete with an expansive additive of the calcium-sulfoaluminate type (E-CSA). NS designates concrete with a shrinkage reducing agent (S). NES-CSA, NES-CSA-S1 and NES-CSA-S2 designate concrete containing both E-CSA and S. LC designates concrete with low-heat Portland cement (L), and LE-CSA, LS, and LES-CSA correspond to concrete consisting of L with E-CSA, S, and both E-CSA and S, respectively. NC1, NE-CSA, NS, NES-CSA, LC, LE-CSA, LS, and LES-CSA use the same quality of aggregate and constitute the B1 series. NES-LIME designates concrete with an expansive additive of the lime type (E-LIME) and shrinkage reducing agents. NES-LIME has the same quality of aggregate as NC2. NC2 and NES-LIME constitute the B2 series. The group with NC3 and NES-CSA -S1, and the group with NC4 and NES-CSA-S2 are constitute the S1 series and S2 series, respectively. In both the $\mathrm{B} 1$ series and $\mathrm{B} 2$ series, $40 \mathrm{~kg} / \mathrm{m}^{3}$ of expansive additive and $6 \mathrm{~kg} / \mathrm{m}^{3}$ of shrinkage reducing agent are used when they are included. NES-CSA-S1 and NES-CSA-S2 have $30 \mathrm{~kg} / \mathrm{m}^{3}$ of expansive additive as well as $6 \mathrm{~kg} / \mathrm{m}^{3}$ of shrinkage reduc- ing agent.

$\mathrm{HC}$ has a water-to-binder ratio of 0.25 with $60 \mathrm{~kg} / \mathrm{m}^{3}$ of silica fume.

\subsection{Testing procedures \\ 3.2.1 Mechanical properties of concrete}

The strength of compressive cylinders of concrete with a specimen size of $\phi 100 \mathrm{~mm} \times 200 \mathrm{~mm}$ was determined according to JIS A 1108 (JSA 2001a). Young's modulus of concrete was determined according to JIS A 1113 at the same time as testing of compressive strength (JSA 2001b). All these tests were conducted at the ages of $0.42,0.5,0.67,1,3,7,14$, and 28 days, and averaged values among three specimens were evaluated at each age. After demolding at a concrete age of one day, the specimens were cured under two conditions: $20^{\circ} \mathrm{C}$ water curing and sealed curing at room temperature with aluminum adhesive tape to prevent the evaporation of water.

\subsubsection{Deformation}

Figure 3 shows the details of specimens for measurement of autogenous or drying deformation strain. All the specimens had the same cross-section as the beams used for self-induced stress (see below). After demolding at a concrete age of one day, all the specimens were sealed with aluminum adhesive tape to prevent the evaporation of water and set at room temperature. For the additional drying shrinkage specimens of the B2 series, the aluminum tape was stripped at 30 days after casting for measuring the drying shrinkage. An embedded strain gauge measuring $\phi 20 \mathrm{~mm} \times 104 \mathrm{~mm}$ and with a reference length of $100 \mathrm{~mm}$ with low elastic modulus of 39 $\mathrm{N} / \mathrm{mm}^{2}$ and a thermocouple were placed at the center of the specimens. Autogenous deformation as well as drying shrinkage of concrete were determined by subtract-

Table 1 Materials.

\begin{tabular}{|c|c|}
\hline Material (Designation) & Type (Designation) / Characteristics \\
\hline \multirow[t]{3}{*}{ Cement (C) } & Normal Portland cement (N) / specific gravity: $3.16 \mathrm{~g} / \mathrm{cm}^{3}$, blaine: $3500 \mathrm{~cm}^{2} / \mathrm{g}$ \\
\hline & Low-heat Portland cement (L) / specific gravity: $3.22 \mathrm{~g} / \mathrm{cm} 3$, blaine: $3310 \mathrm{~cm}^{2} / \mathrm{g}$ \\
\hline & High-early strength Portland cement $(\mathrm{H}) /$ specific gravity: $3.14 \mathrm{~g} / \mathrm{cm}^{3}$; blaine: $4420 \mathrm{~cm}^{2} / \mathrm{g}$ \\
\hline Additive (Ad) & Silica fume (SF) / specific gravity: $2.20 \mathrm{~g} / \mathrm{cm}^{3}$, blaine: $2 \cdot 10^{5} \mathrm{~cm} 2 / \mathrm{g}, \mathrm{SiO}_{2}: 91 \%$ \\
\hline \multirow{2}{*}{$\begin{array}{l}\text { Expansive additive } \\
\text { (EX) }\end{array}$} & Calcium-sulfoaluminate (E-CSA) / specific gravity: $2.96 \mathrm{~g} / \mathrm{cm}^{3}$, blaine: $3050 \mathrm{~cm}^{2} / \mathrm{g}$ \\
\hline & Lime type (E-LIME) / specific gravity: $3.15 \mathrm{~g} / \mathrm{cm}^{3}$, blaine: $3490 \mathrm{~cm}^{2} / \mathrm{g}$ \\
\hline $\begin{array}{l}\text { Shrinkage reducer } \\
\text { agent (SRA) }\end{array}$ & Lower alcohol alkyleneoxide adduct \\
\hline \multirow{2}{*}{$\begin{array}{l}\text { High-range water re- } \\
\text { ducing agent (SP) }\end{array}$} & Polycarboxylic acid based high-range water-reducing agent (SP1) / density $1.07 \mathrm{~g} / \mathrm{cm}^{3}$ \\
\hline & Polycarboxylic acid based high-range water-reducing and air-entraining agent (SP2) \\
\hline \multirow[t]{5}{*}{ Fine aggregate $(\mathrm{S})$} & Land sand (S1) / density: $2.62 \mathrm{~g} / \mathrm{cm}^{3}$, absorption: $1.66 \%$, F.M.: 2.84 \\
\hline & Land sand (S2) / density: $2.61 \mathrm{~g} / \mathrm{cm}^{3}$, absorption: $1.44 \%$, F.M.: 2.82 \\
\hline & River sand (S3) / density: $2.61 \mathrm{~g} / \mathrm{cm}^{3}$, F.M.: 2.69 \\
\hline & Crushed sand (S4) / density: $2.58 \mathrm{~g} / \mathrm{cm}^{3}$, absorption: $1.67 \%$, F.M. 2.75 \\
\hline & Crushed sand (S5) / density: $2.58 \mathrm{~g} / \mathrm{cm}^{3}$, adsorption: $1.67 \%$, F.M.:2.75 \\
\hline \multirow[t]{5}{*}{ Coarse aggregate $(\mathrm{G})$} & Crushed sand stone (G1) / maximum: $20 \mathrm{~mm}$, density: $2.64 \mathrm{~g} / \mathrm{cm}^{3}$, absorption: $0.85 \%$, F.M.: 6.61 \\
\hline & Crushed sand stone (G2) / maximum: $20 \mathrm{~mm}$, density: $2.65 \mathrm{~g} / \mathrm{cm}^{3}$, absorption: $0.74 \%$, F.M.: 6.52 \\
\hline & Crushed sand stone (G3) / maximum: $20 \mathrm{~mm}$, density: $2.63 \mathrm{~g} / \mathrm{cm}^{3}$, F.M.: 6.68 \\
\hline & Crushed sand stone (G4) / maximum: $20 \mathrm{~mm}$, density: $2.69 \mathrm{~g} / \mathrm{cm}^{3}$, absorption: $0.61 \%$, F.M.: 6.38 \\
\hline & Crushed sand stone (G5) / maximum: $20 \mathrm{~mm}$, density: $2.65 \mathrm{~g} / \mathrm{cm}^{3}$, absorption: $0.85 \%$, F.M.: 6.61 \\
\hline
\end{tabular}


Table 2 Mixture proportions (unit content).

\begin{tabular}{|c|c|c|c|c|c|c|c|c|c|c|c|c|c|}
\hline Series & & $\begin{array}{l}\mathrm{W} / \mathrm{B} \\
*\end{array}$ & $\begin{array}{c}\mathrm{W} \\
(\mathrm{kg}) \\
\end{array}$ & $\begin{array}{c}\mathrm{C} \\
(\mathrm{kg}) \\
\end{array}$ & $\begin{array}{l}\text { EX } \\
(\mathrm{kg}) \\
\end{array}$ & $\begin{array}{l}\text { SRA } \\
(\mathrm{kg}) \\
\end{array}$ & $\begin{array}{c}\mathrm{SF} \\
(\mathrm{kg})\end{array}$ & $\begin{array}{c}\mathrm{S} \\
(\mathrm{kg}) \\
\end{array}$ & $\begin{array}{c}\mathrm{G} \\
(\mathrm{kg}) \\
\end{array}$ & $\begin{array}{l}\mathrm{SP} / \mathrm{B}^{*} \\
(\mathrm{~kg})\end{array}$ & $\begin{array}{c}\begin{array}{c}\text { Slump } \\
\text { flow } \\
(\mathrm{mm})\end{array} \\
\end{array}$ & $\begin{array}{c}\text { Air con- } \\
\text { tent } \\
(\%) \\
\end{array}$ & $\begin{array}{l}\text { Temp. } \\
\left({ }^{\circ} \mathrm{C}\right)\end{array}$ \\
\hline B1 & NCI & 0.3 & 175 & $\begin{array}{l}583 \\
(\mathrm{~N})\end{array}$ & - & - & - & $\begin{array}{l}800 \\
\text { (S1) }\end{array}$ & $\begin{array}{c}832 \\
\text { (G1) }\end{array}$ & $\begin{array}{c}0.90 \\
\text { (SP1) }\end{array}$ & 625 & 1.0 & 19.0 \\
\hline B1 & NE-CSA & 0.3 & 175 & $\begin{array}{l}543 \\
(\mathrm{~N})\end{array}$ & $\begin{array}{c}40 \\
(\mathrm{CSA})\end{array}$ & - & - & $\begin{array}{l}798 \\
\text { (S1) }\end{array}$ & $\begin{array}{c}832 \\
\text { (G1) }\end{array}$ & $\begin{array}{c}0.93 \\
\text { (SP1) }\end{array}$ & 425 & 0.6 & 21.2 \\
\hline B1 & NS & 0.3 & 169 & $\begin{array}{l}583 \\
(\mathrm{~N})\end{array}$ & - & 6 & - & $\begin{array}{l}800 \\
\text { (S1) }\end{array}$ & $\begin{array}{c}832 \\
\text { (G1) }\end{array}$ & $\begin{array}{c}1.00 \\
(\mathrm{SP} 1)\end{array}$ & 630 & 1.5 & 18.0 \\
\hline B1 & $\begin{array}{c}\text { NES-CS } \\
\text { A }\end{array}$ & 0.3 & 169 & $\begin{array}{l}543 \\
(\mathrm{~N})\end{array}$ & $\begin{array}{c}40 \\
(\mathrm{CSA})\end{array}$ & 6 & - & $\begin{array}{l}789 \\
\text { (S1) }\end{array}$ & $\begin{array}{c}832 \\
\text { (G1) }\end{array}$ & $\begin{array}{c}1.15 \\
\text { (SP1) }\end{array}$ & 625 & 1.3 & 19.0 \\
\hline B1 & $\mathrm{LC}$ & 0.3 & 175 & $\begin{array}{c}583 \\
(\mathrm{~L})\end{array}$ & - & - & - & $\begin{array}{l}809 \\
\text { (S1) }\end{array}$ & $\begin{array}{c}832 \\
\text { (G2) }\end{array}$ & $\begin{array}{c}0.50 \\
\text { (SP1) }\end{array}$ & 580 & 2.1 & 18.7 \\
\hline B1 & LE-CSA & 0.3 & 175 & $\begin{array}{l}543 \\
\text { (L) }\end{array}$ & $\begin{array}{c}40 \\
(\mathrm{CSA})\end{array}$ & - & - & $\begin{array}{l}806 \\
\text { (S1) }\end{array}$ & $\begin{array}{c}832 \\
\text { (G1) } \\
\end{array}$ & $\begin{array}{c}0.58 \\
\text { (SP1) }\end{array}$ & 580 & 1.3 & 16.9 \\
\hline B1 & LS & 0.3 & 169 & $\begin{array}{l}583 \\
(\mathrm{~L})\end{array}$ & - & 6 & - & $\begin{array}{l}809 \\
\text { (S1) }\end{array}$ & $\begin{array}{c}832 \\
\text { (G1) }\end{array}$ & $\begin{array}{c}0.51 \\
\text { (SP1) }\end{array}$ & 555 & 1.3 & 18.3 \\
\hline B1 & $\begin{array}{c}\text { LES-CS } \\
\text { A }\end{array}$ & 0.3 & 169 & $\begin{array}{l}543 \\
(\mathrm{~L})\end{array}$ & $\begin{array}{c}40 \\
(\mathrm{CSA})\end{array}$ & 6 & - & $\begin{array}{l}806 \\
\text { (S1) }\end{array}$ & $\begin{array}{c}832 \\
\text { (G1) }\end{array}$ & $\begin{array}{c}0.60 \\
\text { (SP1) }\end{array}$ & 665 & 1.2 & 16.6 \\
\hline B2 & NC2 & 0.3 & 175 & $\begin{array}{l}583 \\
(\mathrm{~N})\end{array}$ & - & - & - & $\begin{array}{l}797 \\
\text { (S2) }\end{array}$ & $\begin{array}{c}835 \\
\text { (G2) }\end{array}$ & $\begin{array}{c}0.70 \\
\text { (SP1) }\end{array}$ & 550 & 2.9 & 14.3 \\
\hline B2 & $\begin{array}{c}\text { NES-LI } \\
\text { ME }\end{array}$ & 0.3 & 169 & $\begin{array}{l}543 \\
(\mathrm{~N})\end{array}$ & $\begin{array}{c}40 \\
(\mathrm{LIM} \\
\mathrm{E})\end{array}$ & 6 & - & $\begin{array}{l}797 \\
\text { (S2) }\end{array}$ & $\begin{array}{l}835 \\
\text { (G2) }\end{array}$ & $\begin{array}{c}0.60 \\
\text { (SP1) }\end{array}$ & 475 & 1.6 & 15.3 \\
\hline & $\mathrm{HC}$ & 0.25 & 150 & $\begin{array}{l}540 \\
(\mathrm{H})\end{array}$ & - & - & 60 & $\begin{array}{l}766 \\
\text { (S3) } \\
\end{array}$ & $\begin{array}{l}940 \\
\text { (G3) }\end{array}$ & $\begin{array}{c}2.2 \\
\text { (SP2) }\end{array}$ & 685 & 2.7 & 13.5 \\
\hline S1 & NC3 & 0.23 & 161 & $\begin{array}{l}630 \\
(\mathrm{~N})\end{array}$ & - & - & 70 & $\begin{array}{l}626 \\
\text { (S4) }\end{array}$ & $\begin{array}{l}912 \\
\text { (G4) }\end{array}$ & $\begin{array}{c}1.3 \\
\text { (SP2) }\end{array}$ & 45.0 & 0.8 & 17.6 \\
\hline S1 & $\begin{array}{c}\text { NES-CS } \\
\text { A } \\
\text {-S1 }\end{array}$ & 0.23 & 161 & $\begin{array}{l}600 \\
(\mathrm{~N})\end{array}$ & $\begin{array}{c}30 \\
(\mathrm{CSA})\end{array}$ & 6 & 70 & $\begin{array}{l}630 \\
\text { (S4) }\end{array}$ & $\begin{array}{l}913 \\
\text { (G4) }\end{array}$ & $\begin{array}{c}1.0 \\
(\mathrm{SP} 2)\end{array}$ & 42.0 & 1.6 & 17.3 \\
\hline S2 & $\mathrm{NC4}$ & 0.23 & 161 & $\begin{array}{l}630 \\
(\mathrm{~N}) \\
\end{array}$ & - & - & 70 & $\begin{array}{l}629 \\
\text { (S5) }\end{array}$ & $\begin{array}{l}916 \\
\text { (G5) }\end{array}$ & $\begin{array}{c}3.16 \\
\text { (SP2) }\end{array}$ & 600 & 0.7 & 18.7 \\
\hline S2 & $\begin{array}{c}\text { NES-CS } \\
\text { A } \\
-\mathrm{S} 2 \\
\end{array}$ & 0.23 & 161 & $\begin{array}{l}600 \\
(\mathrm{~N})\end{array}$ & $\begin{array}{c}30 \\
(\mathrm{CSA})\end{array}$ & 6 & 70 & $\begin{array}{l}632 \\
\text { (S5) }\end{array}$ & $\begin{array}{l}920 \\
\text { (G5) }\end{array}$ & $\begin{array}{c}2.6 \\
(\mathrm{SP} 2)\end{array}$ & 575 & 0.8 & 17.1 \\
\hline
\end{tabular}

\footnotetext{
$* \mathrm{~B}=\mathrm{C}+\mathrm{EX}+\mathrm{SF}$
}

ing thermal strain from measured strain. The coefficient of thermal expansion of concrete was assumed to be 10 $\times 10^{-6} /{ }^{\circ} \mathrm{C}$. Measurement was begun immediately after the concrete was poured.

\subsubsection{Uniaxial compressive creep test}

A uniaxial compressive creep test focusing on early age behavior was conducted with NC2, NES-LIME, and HC. These three mixture proportions were selected to evaluate the final creep coefficient and the rate of creep development regardless of cement type and additive. The loading ages and numbers of specimens are listed in Table 3. Specimens measuring $200 \times 250 \times 300 \mathrm{~mm}^{3}$ were prepared, and after demolding at a concrete age of one day, all the specimens were sealed with aluminum adhesive tape to prevent the evaporation of water and set at room temperature. Additional NC2 and NES-LIME specimens were prepared for measuring drying creep, and the aluminum tape was stripped 30 days after casting. An embedded strain gauge and a thermocouple identical to those used in specimens for

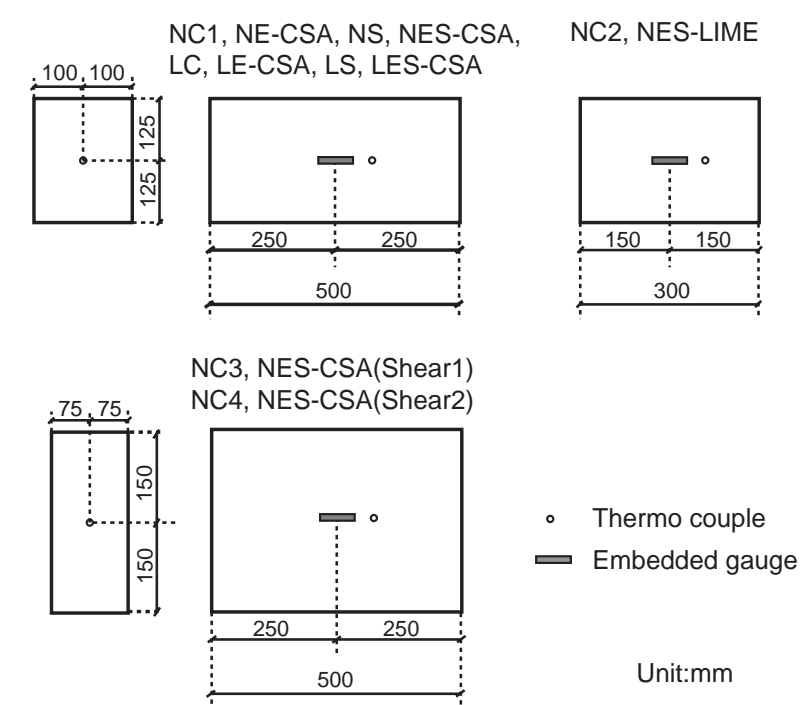

Fig. 3 Details of specimen for autogenous deformation. 
Table 3 Loading age for creep test.

\begin{tabular}{|c|c|c|}
\hline \multirow{2}{*}{ Mixture proportion } & $\begin{array}{c}\text { Loading age } \\
\text { Number of specimens }\end{array}$ \\
\hline \multirow{2}{*}{ NC2, NES-LIME } & 1.24 & 1 \\
\cline { 2 - 3 } & 2.26 & 1 \\
\cline { 2 - 3 } & 16.6 & 2 \\
\hline \multirow{2}{*}{ HC } & 0.44 & 2 \\
\cline { 2 - 3 } & 0.85 & 2 \\
\hline
\end{tabular}

autogenous deformation were placed at the center of each specimen. The creep strain of each specimen was determined by subtracting the thermal strain and the autogenous or drying deformation strain from the measured strain under the same condition. The autogenous deformation strain and drying shrinkage strain were determined from each specimen for the deformation measurement mentioned above and thermal strain was obtained by assuming a thermal expansion coefficient of $10 \times 10^{-6} /{ }^{\circ} \mathrm{C}$.

The load during the creep test is fixed at a stress/strength ratio of $20 \%$. The strength of the concrete is tested at the loading age. Fig. 4 shows details of the experimental equipment for the uniaxial compressive creep test. The stress fluctuation of the accumulation is controlled within $\pm 5 \%$ of the targeting stress.

\subsubsection{Self-induced stress in reinforced concrete beam}

The details of reinforced concrete $(\mathrm{RC})$ beam specimens for measuring self-induced stress are shown in Fig. 5 and details of the properties of reinforcing bars are listed in Table 4. One specimen was prepared for each mixture proportion. The beams for the B1 series measured $200 \mathrm{~mm}$ (width) $\times 250 \mathrm{~mm}$ (height) $\times 2700 \mathrm{~mm}$ (length) and reinforcing bars measuring $19 \mathrm{~mm}$ in diameter and with a Young's modulus of $190000 \mathrm{~N} / \mathrm{mm}^{2}$ were set at a depth of $210 \mathrm{~mm}$ from the extreme compressive fiber with a hook bended at both ends. Wire strain gauges were attached on the upper and bottom sides of the reinforcing bars at mid-span.

The beams for the B2 series measured $200 \mathrm{~mm}$ (width) $\times 250 \mathrm{~mm}$ (height) $\times 2400 \mathrm{~mm}$ (length). The reinforcing bars used for the B2 series measured $19 \mathrm{~mm}$ in diameter (D19), had a Young's modulus of 197000 $\mathrm{N} / \mathrm{mm}^{2}$ and were grooved along their length at two opposite sides for attaching wire strain gauges. These reinforcing bars were set at a depth of $210 \mathrm{~mm}$ from the extreme compressive fiber without using hooks.

The beams for both $\mathrm{S} 1$ and $\mathrm{S} 2$ had the same section and longitudinal size $(150 \mathrm{~mm} \times 300 \mathrm{~mm} \times 2300 \mathrm{~mm})$. However, the S1 series had a tension reinforcing bar of D22, and 7 grooved stirrups were used over a length of $750 \mathrm{~mm}$. The S2 series had main reinforcing bars of D25, and 13 grooved stirrups were used over a length of $750 \mathrm{~mm}$. Both series had compressive reinforcing bars of D10. The wire strain gauges were attached on the upper and bottom sides of the reinforcing bars at mid-span and in the grooved stirrups.

Teflon sheets $1.0 \mathrm{~mm}$ thick at the bottom of the mold, polystyrene board $3 \mathrm{~mm}$ thick on both ends of the mold, and polyester film $0.1 \mathrm{~mm}$ thick on all the sides and bottom of the mold were applied to reduce friction between the mold and the specimen. After demolding, all the specimens were sealed with aluminum adhesive tape to prevent the evaporation of water and they were cured at room temperature. The demolding time of LS and LES was 2 days after mixing, and the demolding time for all the other types was 1 day after mixing.

Self-induced stress of concrete was obtained from the measured strain of the reinforcing bars. The averaged strain of reinforcing bars (upper and bottom measurement for the B1, S1, and S3 series, and measurement of both sides for the B2 series) was corrected by subtracting the thermal strain measured by a dummy steel bar in the beam.

Self-induced stress in concrete at the extreme bottom fiber due to restraint of reinforcing bars was determined by considering the equilibrium of force among the concrete and the reinforcing bars as well as the assumption of linear strain distribution:

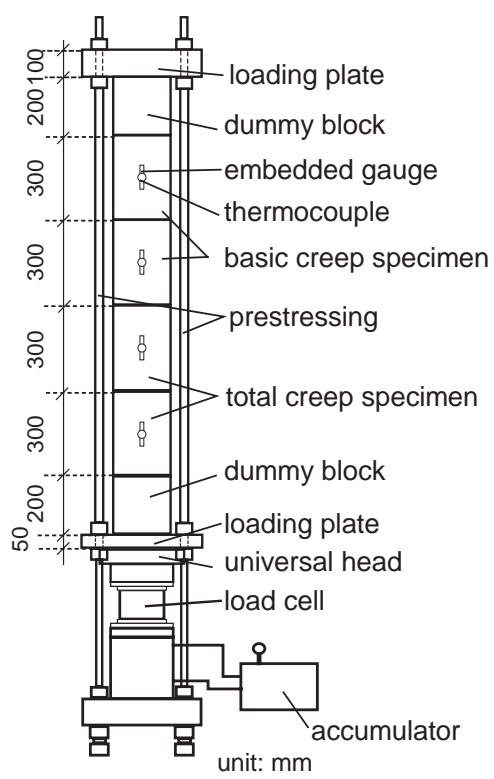

Fig. 4 Experimental equipment for uniaxial compressive creep test. 
B1

NC1, NE-CSA, NS, NES-CSA,

LC, LE-CSA, LS, LES-CSA

Tension reinforcement ratio $(\mathrm{p}=\mathrm{As} / \mathrm{bh}): 1.14 \% \cdot \mathrm{D} 19$
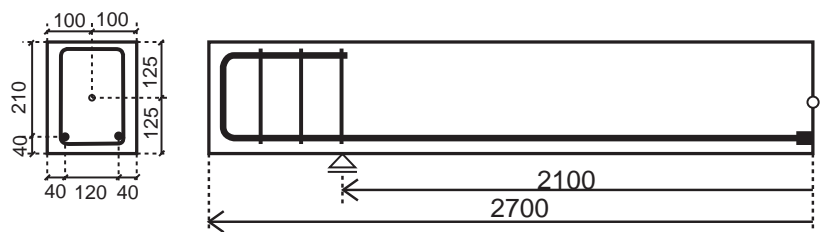

NC2, NES-LIME

$\mathrm{p}=\mathrm{As} / \mathrm{bh}: 0.97 \% \cdot$ :D19 grooved
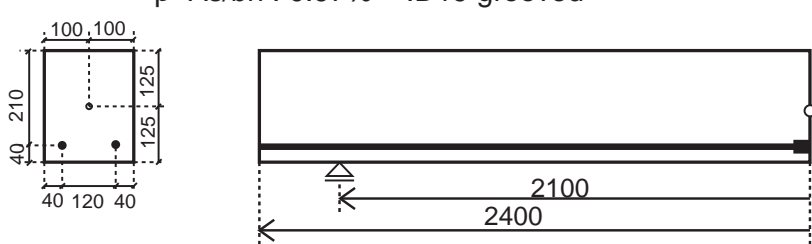

S1

C3, NES-CSA-S1

Tension: $\quad \mathrm{p}=\mathrm{As} / \mathrm{bh}: 1.72 \% \quad \bullet: \mathrm{D} 22$

Compression: $\quad p=A s^{\prime} / b h: 0.31 \% \cdot D 10$

Shear: $\quad \mathrm{pw}=0.49 \% \quad \bullet: \mathrm{D} 10$ grooved
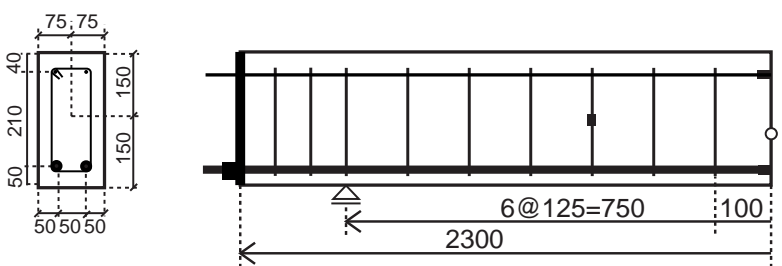

S2

NC4, NES-CSA-S2

Tension: $\quad \mathrm{p}=\mathrm{As} / \mathrm{bh}: 2.25 \% \quad \bullet: \mathrm{D} 25$

Compression: $\mathrm{p}=\mathrm{As} / \mathrm{bh}: 0.31 \% \quad \bullet: \mathrm{D} 10$

Shear: $\quad \mathrm{pw}=0.98 \% \quad \bullet: \mathrm{D} 10$ grooved
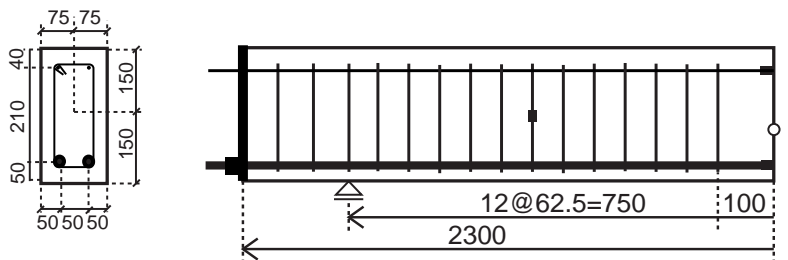

unit:mm

Wire strain gauge o Thermo couple

Fig.5 Details of RC beam specimen for measuring self-induced stress.

Table 4 Properties of reinforcing bar in $\mathrm{RC}$ beam.

\begin{tabular}{|c|l|}
\hline SD295A (SD1) & $\phi: 19 \mathrm{~mm}$, Young's modulus: $190 \mathrm{kN} / \mathrm{mm}^{2}$, Yield strength: $331 \mathrm{~N} / \mathrm{mm}^{2}$ \\
\hline SD295A (SD2) & $\begin{array}{l}\phi: 19 \mathrm{~mm} \text {, Young's modulus: } 197 \mathrm{kN} / \mathrm{mm}^{2} \text {, Yield strength: } 347 \mathrm{~N} / \mathrm{mm}^{2}, \\
\text { Grooved Area } 241 \mathrm{~mm}^{2}\end{array}$ \\
\hline High-Tension Steel (HT) & $\phi: 22 \mathrm{~mm}$, Young's modulus: $201 \mathrm{kN} / \mathrm{mm}^{2}$, Yield strength: $1162 \mathrm{~N} / \mathrm{mm}^{2}$ \\
\hline SD295 (SD3) & $\begin{array}{l}\phi: 10 \mathrm{~mm} \text {, Young's modulus: } 195 \mathrm{kN} / \mathrm{mm}^{2} \text {, Yield strength: } 354 \mathrm{~N} / \mathrm{mm}^{2}, \\
\text { Grooved Area } 45.9 \mathrm{~mm}^{2}\end{array}$ \\
\hline SD295 (SD4) & $\phi: 10 \mathrm{~mm}$, Young's modulus: $197 \mathrm{kN} / \mathrm{mm}^{2}$, Yield strength: $378 \mathrm{~N} / \mathrm{mm}^{2}$ \\
\hline High-Tension Steel (HT2) & $\phi: 22 \mathrm{~mm}$, Young's modulus: $201 \mathrm{kN} / \mathrm{mm}^{2}$, Yield strength: $1162 \mathrm{~N} / \mathrm{mm}^{2}$ \\
\hline SD295 (SD5) & $\begin{array}{l}\phi: 10 \mathrm{~mm} \text {, Young's modulus: } 198 \mathrm{kN} / \mathrm{mm}^{2} \text {, Yield strength: } 370 \mathrm{~N} / \mathrm{mm}^{2}, \\
\text { Grooved Area 42.2 mm }\end{array}$ \\
\hline SD295 (SD6) & $\phi: 10 \mathrm{~mm}$, Young's modulus: $200 \mathrm{kN} / \mathrm{mm}^{2}$, Yield strength: $386 \mathrm{~N} / \mathrm{mm}^{2}$ \\
\hline
\end{tabular}

$$
\begin{aligned}
\sigma_{c}= & -P_{s t} / A_{c}\left[1+A_{c}\left(d-C_{g}\right)\left(h-C_{g}\right) / I_{c}\right] \\
& -P_{s c} / A_{c}\left[1+A_{c}\left(d^{\prime}-C_{g}\right)\left(h-C_{g}\right) / I_{c}\right] \\
P_{s t}= & A_{s t} E_{s t} \varepsilon_{s t}, P_{s c}=A_{s c} E_{s c} \varepsilon_{s c}
\end{aligned}
$$

where, $P_{s t}, P_{s c}$ : force in the tensile and compressive reinforcing bars, $A_{c}$ : Cross sectional area of concrete in section of beam, $A_{s t}, A_{s c}$ : Cross sectional area of tensile and compressive reinforcing bars, $E_{s t}, E_{s c}$ :Young's modulus of tensile and compressive reinforcing bars, $\varepsilon_{s t}, \varepsilon_{s c}$ : strain in tensile and compressive reinforcing bars, $\sigma_{c}$ : stress of concrete at extreme bottom fiber.

\section{Experimental results and material model for analysis}

This section presents the experimental results and the material models needed for the FE analysis and the beam theory analysis.

\subsection{Compressive strength and Young's modulus}

Table 5 lists the compressive strength of sealed concrete at room temperature as well as Young's modulus and Poisson's ratio. In addition, for comparison with development of cement hydration, the compressive strengths of concrete saturated at $20^{\circ} \mathrm{C}$ are also listed in this table.

Development of Young's modulus of each concrete is modeled as a function of temperature adjusted concrete age (JCI 1999b):

$$
E c(t)=E_{c, t 28} \exp \left(s\left(1-\left(\frac{t_{e, 28}-a}{t-a}\right)^{0.5}\right)\right)
$$


Table 5 Mechanical properties of sealed and saturated concrete at 28 days.

\begin{tabular}{|c|c|c|c|c|c|c|c|}
\hline & $\begin{array}{c}\text { Compressive } \\
\text { strength } \\
\left(\begin{array}{c}\text { saturated }) \\
\left(\mathrm{N} / \mathrm{mm}^{2}\right)\end{array}\right.\end{array}$ & $\begin{array}{c}\text { Compressive } \\
\text { strength } \\
(\mathrm{seal}) \\
\left(\mathrm{N} / \mathrm{mm}^{2}\right)\end{array}$ & $\begin{array}{c}\text { Young's } \\
\text { modulus } \\
(\mathrm{seal}) \\
\left(\mathrm{kN} / \mathrm{mm}^{2}\right)\end{array}$ & Parameter a & Parameter s & $t_{e, 28}$ & $\begin{array}{c}\text { Poisson's } \\
\text { ratio }\end{array}$ \\
\hline $\mathrm{NC1}$ & 85.3 & 77.0 & 35.5 & 0.20 & 0.14 & 24.2 & 0.20 \\
\hline NE-CSA & 74.4 & 64.0 & 33.4 & 0.20 & 0.11 & 24.1 & 0.19 \\
\hline NS & 81.2 & 84.6 & 39.2 & 0.15 & 0.17 & 24.3 & 0.20 \\
\hline NES-CSA & 82.4 & 87.2 & 37.7 & 0.20 & 0.14 & 24.0 & 0.17 \\
\hline LC & 73.5 & 66.8 & 37.0 & 0.32 & 0.17 & 22.1 & 0.16 \\
\hline LE-CSA & 83.3 & 69.8 & 37.3 & 0.30 & 0.15 & 22.1 & 0.18 \\
\hline LS & 70.5 & 65.8 & 34.7 & 0.35 & 0.16 & 22.8 & 0.20 \\
\hline LES-CSA & 76.1 & 66.6 & 36.4 & 0.35 & 0.21 & 21.7 & 0.15 \\
\hline NC2 & 91.4 & 80.3 & 39.6 & 0.23 & 0.15 & 15.9 & $0.19 *$ \\
\hline NES-LIME & 83 & 76.3 & 37.3 & 0.16 & 0.18 & 16.0 & $0.21 *$ \\
\hline HC & 121.7 & 106.5 & 37.5 & 0.12 & 0.15 & 17.4 & - \\
\hline NC3 & 103.3 & 97.8 & 43.5 & 0.25 & 0.13 & 23.6 & 0.20 \\
\hline NES-CSA-S1 & 98.4 & 84.2 & 42.3 & 0.40 & 0.18 & 23.5 & 0.19 \\
\hline NC4 & 125.6 & 114.9 & 40.1 & 0.31 & 0.09 & 23.4 & 0.20 \\
\hline NES-CSA-S2 & 108.6 & 97.1 & 37.7 & 0.40 & 0.16 & 23.6 & 0.19 \\
\hline
\end{tabular}

*: value of concrete specimen curing in water at $20^{\circ} \mathrm{C}$ at 28 th day

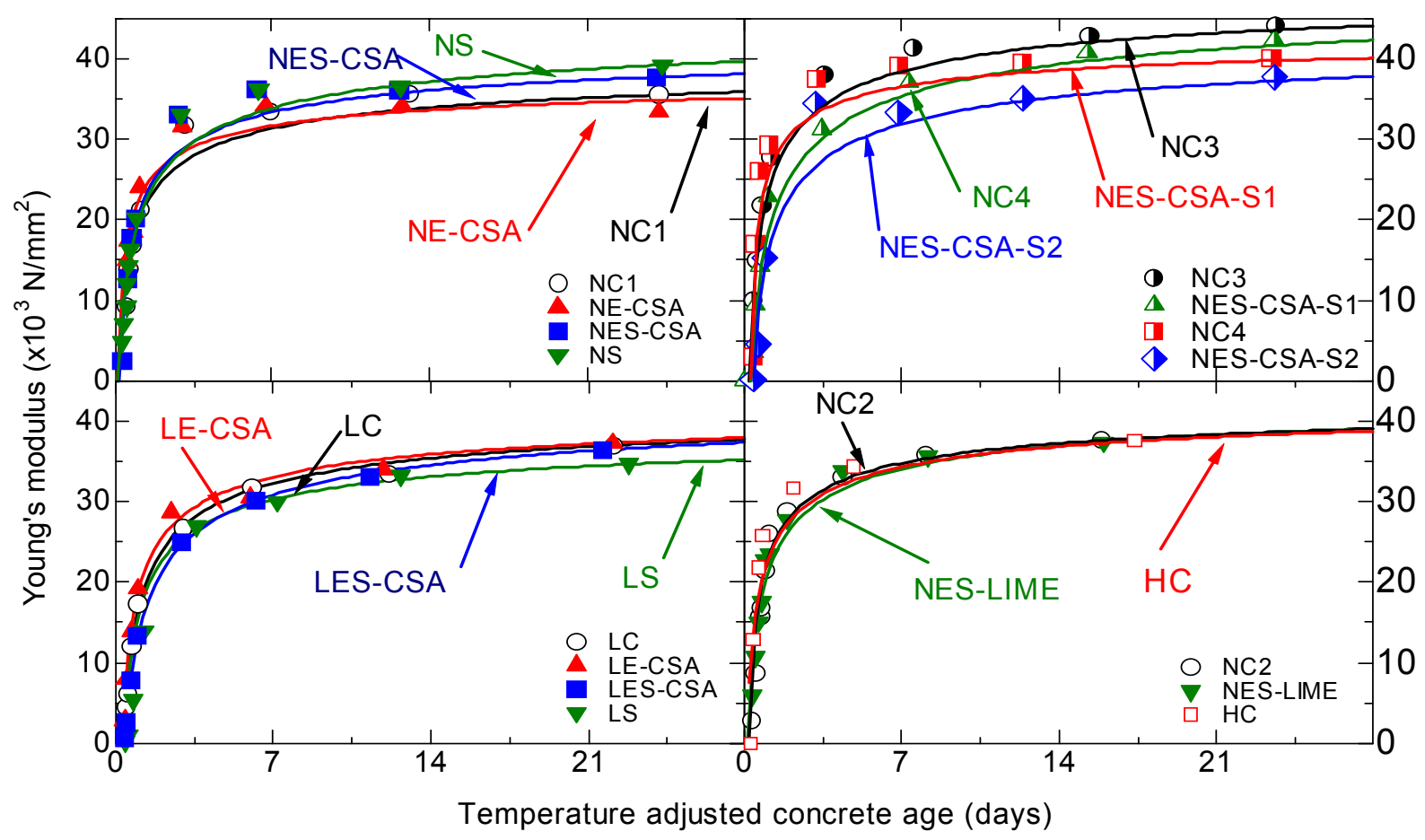

Fig. 6 Experimental results of Young's modulus with regression curve by Eq. 23 .

where, $t_{e, 28}$ : temperature adjusted concrete age at 28 days, $E_{c, t 28}$ : Young's modulus of sealed concrete at 28 days, $a, s:$ material parameters.

According to the regression results, the modeling parameters as well as $t_{e, 28}$ are listed in Table 5. Experimental results and regression curves are shown in Fig. 6. Regarding parameter $a$, which corresponds to the initial setting time effect, the first time during which stress was measured in the self-induced stress test was used for the regression curves.

\subsection{Deformation}

The experimental results on autogenous deformation for the B1 and B2 series are shown in Fig. 7. As a reference, the experimental results for NE-CSA-S1 and NE-CSA-S2 are plotted as well. The data are plotted as a function of temperature adjusted concrete age from the point of view of the hydration process. Using low-heat 


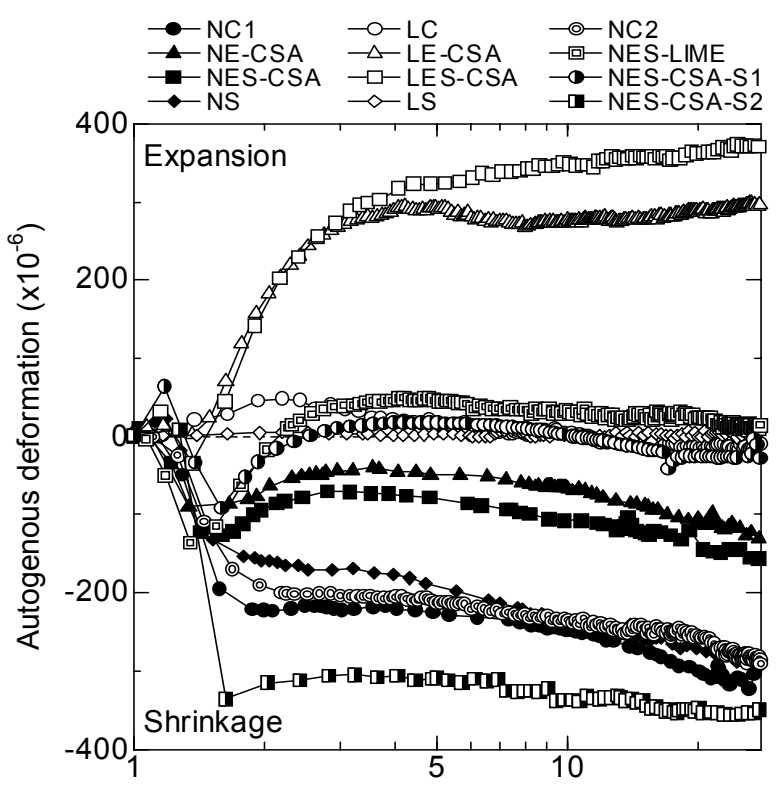

Temperature adjusted concrete age $(t+1$ days)

Fig. 7 Autogenous deformation of concrete.

Portland cement, shrinkage reducing agent, and expansive additive, or a combination thereof is effective for compensating autogenous shrinkage. All the concrete that has expansive additive and/or shrinkage reducing agent shows smaller autogenous shrinkage, and especially some concrete (NC2, LE-CSA, and LES-CSA) that uses expansive additive shows expansion rather than shrinkage, even though they are high-strength concrete. The effect of compensation for autogenous shrinkage at 28 days in temperature adjusted time is shown in Fig. 8.

At 28 days in temperature adjusted concrete age, $\mathrm{NC} 1$ showed a shrinkage value of $330 \times 10^{-6}$. On the other hand, NS showed a shrinkage value of $300 \times 10^{-6}$, thus approximately a $10 \%$ decrease compared to $\mathrm{NC} 1$, and it was confirmed that the reduction in surface tension in capillary water leads to a decrease of shrinkage.

NE-CSA and NES-CSA that include expansive additive of the CSA type showed shrinkage of $130 \times 10^{-6}$ and $160 \times 10^{-6}$, respectively, indicating that the use of expansive additive has a marked compensating effect for autogenous shrinkage. However, it should be noted that the concomitant use effect, which means that compensated strain by concomitant use of shrinkage reducing agent and expansive additive is larger than the summation of each compensated strain, as reported by Tanimura (Tanimura et al. 2000), could not be observed in the case of NES-CSA. This can be explained by the fact that the peak value of temperature history of NE-CSA is approximately $10{ }^{\circ} \mathrm{C}$ higher than that of NES-CSA. This difference implies different reaction between expansive additive and cement hydration in NE-CSA and NES-CSA. The quantity of expansion may be determined by the timing of the reaction of expansive

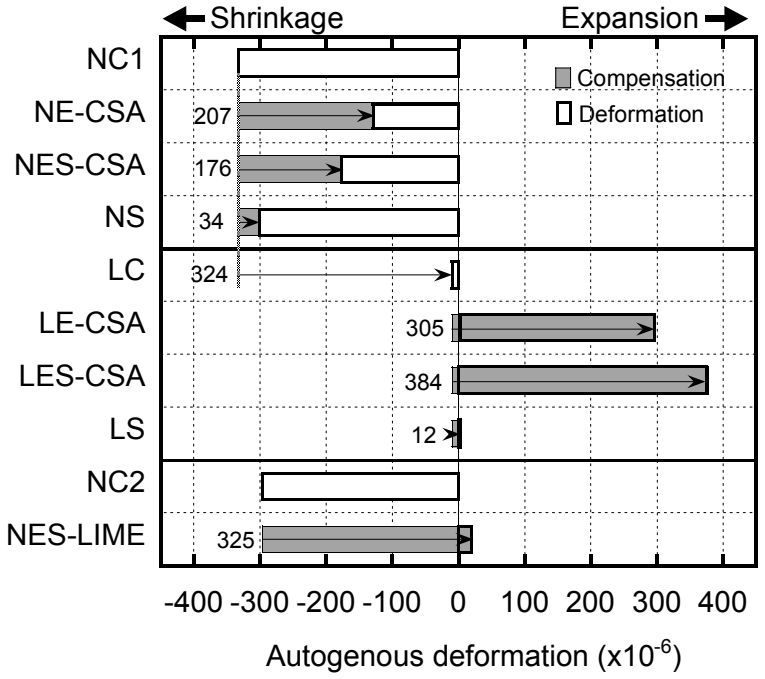

Fig. 8 Autogenous deformation at 28 days in temperature adjusted concrete age and effect of compensation for autogenous shrinkage by low-heat Portland cement, shrinkage reducing agent, expansive additive, or combination thereof.

additive under hardening cement paste. In this case, the high temperature history fails to catch the efficient timing for expansion. On the other hand, another explanation can be considered, as follows. The thermal coefficient is normally a function of hydration progress (e.g. Yang et al. 1999), and the thermal coefficient at an early age in particular showed a larger value than $10 \times 10^{-6}$, which was assumed for the calculation of thermal strain of shrinkage specimens. Thus, the smaller thermal coefficient, which is not the case in reality, with higher temperature history underestimates autogenous shrinkage in the case of NE-CSA.

The concretes with low-heat Portland cement showed smaller autogenous deformation. At 28 days in temperature adjusted time, LC showed a shrinkage of $10 \times$ $10^{-6}$, LS showed non shrinkage, and LE-CSA and LES-CSA showed expansion of $295 \times 10^{-6}$ and $374 \times$ $10^{-6}$, respectively.

A concomitant effect of using both expansive additive and shrinkage reducing agent was observed for the concrete with low-heat Portland cement, i.e., the compensation quantity of LES-CSA, which is $384 \times 10^{-6}$, was more than the summation of those of LE-CSA and LS corresponding to $305 \times 10^{-6}$ and $12 \times 10^{-6}$, respectively.

The compensation quantity of NES-LIME was much larger than that of NES-CSA, and NES-LIME showed an expansion at 28 days in temperature adjusted concrete age.

For the B2 series, the drying condition was imposed after 30 days casting, which corresponds to about 16 days in temperature adjusted concrete age. Fig. 9 shows the comparison of drying shrinkage with autogenous shrinkage. After 370 days in temperature adjusted age, NC2 showed a difference of $70 \times 10^{-6}$ between drying 


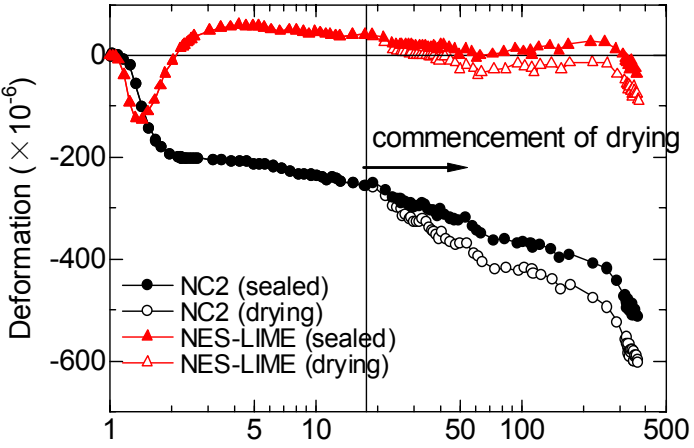

Temperature adjusted concrete age $(\mathrm{t}+1$ days)

Fig. 9 Deformation of NC2 and NES-LIME under sealed condition or drying condition.

shrinkage and autogenous shrinkage. On the other hand, the difference of NES-LIME was $50 \times 10^{-6}$. These experimental results indicate that shrinkage reducing agent is effective in drying shrinkage .

\subsection{Creep properties}

The results of specific creep strain for $\mathrm{NC} 2$ and NES-LIME in the sealed condition and drying condition are shown in Fig. 10 and Fig. 11, respectively. The specific creep strain of NES-LIME under the sealed condition was larger than that of NC2. This result indicates that expansive concrete has a large number of pores, which can be deduced from the fact that NES-LIME has a smaller compressive strength than $\mathrm{NC} 2$.

On the other hand, the specific creep strain under the drying condition of NES-LIME was almost the same as that of NC2. This result indicates that the drying creep of NC2 is much larger than that of NES-LIME. Regarding this aspect, creep strain under the drying condition was compared with creep strain under the sealed condition, as shown in Fig. 12. From this figure, it is obvious that creep strain of NC2 is much more affected by the drying condition than that of NES-LIME. This tendency coincides with the above-mentioned drying shrinkage

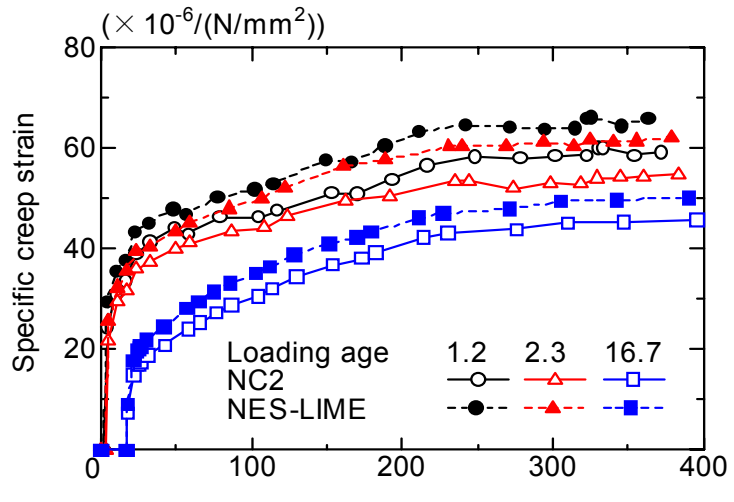

Temperature adjusted concrete age (days)

Fig. 10 Specific creep of NC2 and NES-LIME under sealed condition.

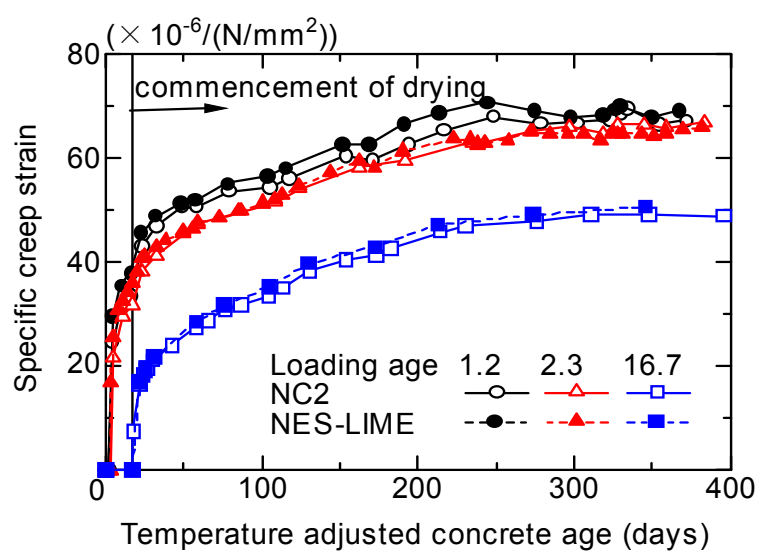

Fig. 11 Specific creep of NC2 and NES-LIME under drying condition.

tendency. From these experimental results, it is reasonable to conclude that the shrinkage reducing agent reduces drying creep. The experimental results of the specific creep strain also indicate that high-strength con-

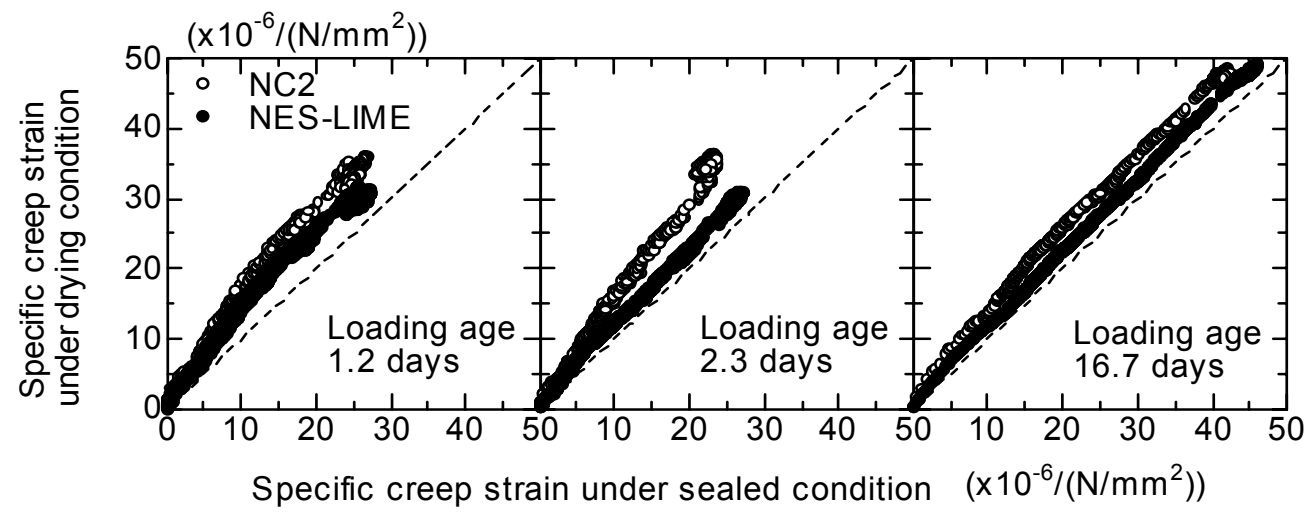

Fig. 12 Difference of specific creep under sealed condition and under drying condition. Commencement of drying is 30 days after casting and defined as day zero in this plot. 


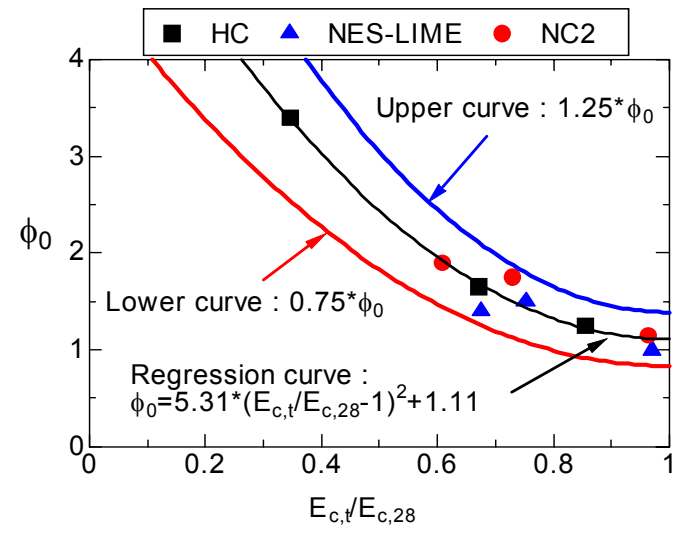

Fig. 13 Ultimate creep coefficient $\phi_{0}$ as a function of relative Young's modulus $\left(E_{c}(t) / E_{c, 28}\right)$.

crete with expansive additive is comparable to normal high-strength concrete with regard to mechanical properties.

For NC2, NES-LIME, HC, the value of the creep coefficient is determined by the ratio of creep strain to elastic strain represented by Young's modulus of sealed concrete at 28 days in temperature adjusted concrete age. The development of the creep coefficient was modeled for analysis by using an equation whose concept is based on CEB-FIP MODEL CODE 1990 (CEB-FIP 1990):

$$
\begin{aligned}
& \phi\left(t, t_{0}\right)=\phi_{0}\left[\frac{\left(t-t_{0}\right) / t_{1}}{\beta_{H}+\left(t-t_{0}\right) / t_{1}}\right]^{0.3} \\
& \phi_{0}=5.31 \cdot\left(E_{c}\left(t_{0}\right) / E_{c, 28}-1.0\right)^{2}+1.11 \\
& \left\{\begin{array}{c}
0 \leq E_{c}(t) / E_{c, 28}<0.346 \\
\beta_{H}=0.000001 \\
0.346 \leq E_{c}(t) / E_{c, 28}<1.0 \\
\beta_{H}=40.5 \cdot\left(E_{c}(t) / E_{c, 28}-0.346\right)+0.485
\end{array}\right.
\end{aligned}
$$

where, $\phi\left(t, t_{0}\right)$ : basic creep coefficient, $\phi_{0}$ : ultimate basic creep coefficient, $\beta_{H}$ : coefficient representing the effect of loading age on rate of creep development, $t$ : temperature adjusted concrete age (days), $t_{0}$ : temperature adjusted concrete age of loading age, $t_{1}: 1$ day, $\left(E_{c}(t) / E_{c, 28}\right)$ : relative Young's modulus, i.e., the ratio of Young's modulus of sealed concrete at $t$ to that of sealed concrete at 28 days in temperature adjusted concrete age.

The value of $E_{c, 28}$ was obtained by extrapolating the regression curve of Eq. 23. $\phi_{0}$ and $\beta_{H}$ of each experimental result were calculated by regression with Eq. 23 . The relation between $\phi_{0}$ and $\left(E_{c}(t) / E_{c, 28}\right)$, and that between $\beta_{H}$ and $\left(E_{c}(t) / E_{c, 28}\right)$ are shown in Fig. 13 and Fig. 14, respectively.

In these figures, the regression curve as a function of relative Young's modulus, which are Eqs. 25 and 26, are shown. Also, cover-all curves for the data spread are shown with indications of "upper curve" and "lower

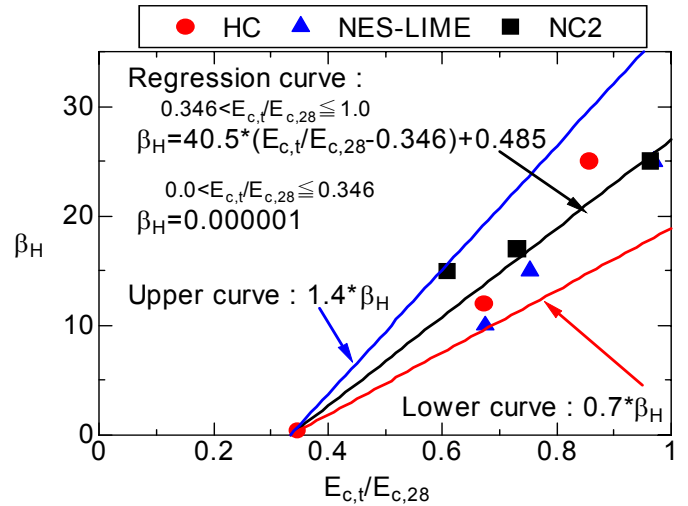

Fig. 14 Coefficient representing effect of loading age on rate of creep development $\beta_{H}$ as a function of relative Young's modulus $\left(E_{c}(t) / E_{c, 28}\right)$.

curve" in Fig. 13 and Fig. 14. These curves will be discussed in the next chapter.

\subsection{Self-induced stress}

Self-induced stress histories in concrete at the extreme bottom fiber of the B1 and B2 series are shown in Fig. 15. The self-induced stress of concrete at 18.5 days in temperature adjusted concrete age, with indication of the stress compensation quantity, is represented in Fig. 16.

NC1 showed tensile stress of $0.94 \mathrm{~N} / \mathrm{mm}^{2}$ and NS showed tensile stress of $0.88 \mathrm{~N} / \mathrm{mm}^{2}$, meaning that shrinkage reducing agent is effective for tensile stress compensation of $6 \%$. Compressive stress was recorded in NE-CSA and NES-CSA with values of $0.03 \mathrm{~N} / \mathrm{mm}^{2}$ and $0.04 \mathrm{~N} / \mathrm{mm}^{2}$, respectively. Expansive additive is

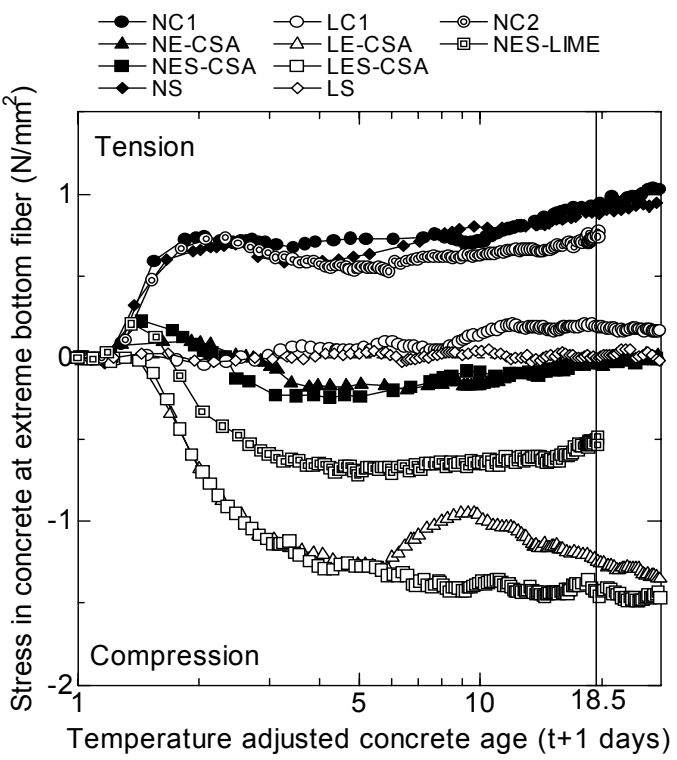

Fig. 15 Self-induced stress in concrete at extreme bottom fiber. 


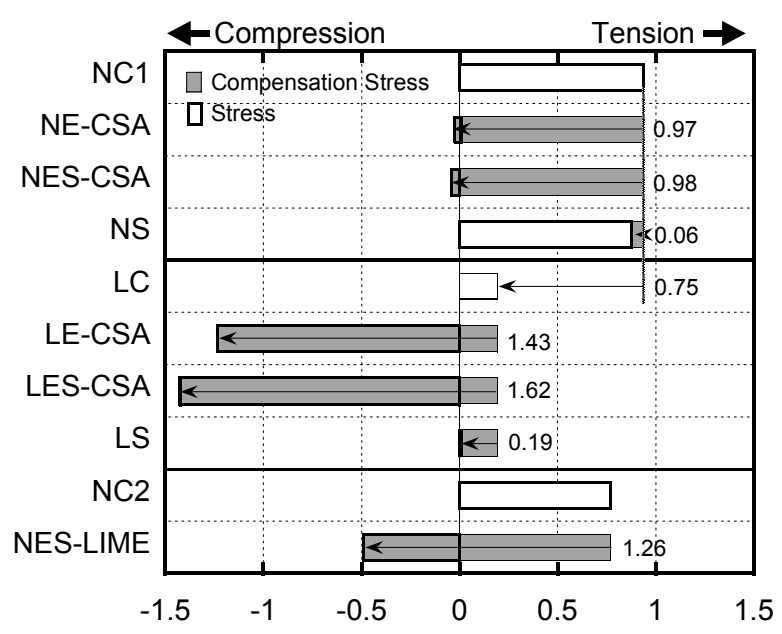

Stress in concrete at extreme tension fiber $\left(\mathrm{N} / \mathrm{mm}^{2}\right)$

Fig. 16 Self-induced stress in concrete at extreme bottom fiber at 18.5 days in temperature adjusted concrete age and compensation of tensile stress by low-heat cement, shrinkage reducing agent, expansive additive, or combination thereof.

thus quite effective in reducing tensile self-induced stress.

Concretes with low-heat Portland cement showed small shrinkage or expansion. Stress in LC and LS were $0.19 \mathrm{~N} / \mathrm{mm}^{2}$ in tension and $0 \mathrm{~N} / \mathrm{mm}^{2}$. LE-CSA and LES-CSA showed compressive stress of $1.24 \mathrm{~N} / \mathrm{mm}^{2}$ and $1.43 \mathrm{~N} / \mathrm{mm}^{2}$, respectively. NES-LIME stored compressive stress of $0.49 \mathrm{~N} / \mathrm{mm}^{2}$, which is the compensation quantity of $1.26 \mathrm{~N} / \mathrm{mm}^{2}$ to $\mathrm{NC} 2$.

The tendency of compensation for stress corresponds to the tendency of compensation for shrinkage.

It is concluded that using low-heat Portland cement, shrinkage reducing agent, expansive additive, or a combination thereof is effective for compensating self-induced tensile stress. Their effects for tensile stress compensation are cumulative because their mechanisms are different and independent.

It is worthy of note that the quantity of compensation for shrinkage is no longer a simple relationship with the quantity of compensation of tensile stress. For instance, NE-CSA and NES-CSA stored slightly compressive stress in beam specimen at 28 days, although they showed shrinkage in free deformation at the same time. It follows from this fact that the stress of concrete under restraint condition is determined by the balance of concrete deformation and development of elastic modulus and creep behavior. In order to illustrate such phenomenon, in Fig. 17, which shows the case of NE-CSA, autogenous deformation strain of concrete is compared to the strain of the reinforcing bar. To begin with, autogenous shrinkage is seen as a line that declines down to the left and brings a $-20 \times 10^{-6}$ level of strain in the reinforcing bar. This mild slope means weak stress transmission from the concrete to the reinforcing bar. Next, the autogenous deformation changes into expansion and at the same time the slope becomes steeper, rising to a peak in the upper right. During this stage, concrete deformation is strongly transmitted as deformation of the reinforcing bar and compressive stress is stored in the concrete. This is the schematic of stored compression in concrete.

Hence, it is vitally important to develop a model that takes into account the changing concrete properties with cement hydration in order to evaluate the effect of materials on compensation for self-induced tensile stress.

Additionally, in Fig. 17, a mild slope is observed after the expansion peak again. This tendency, which is observed in NES-CSA as well as NES-LIME, indicates weaker transmission of deformation to the reinforcing bar after deformation peaks. The weaker transmission without deformation peak is also observed in the case of NC1 shown in Fig. 18. On the other hand, LE shows an increase in transmission of deformation to the reinforcing bar as shown in Fig. 19.

\section{Analysis}

\subsection{Basic assumptions for analysis}

The proposed FE analysis requires modeling of the de-

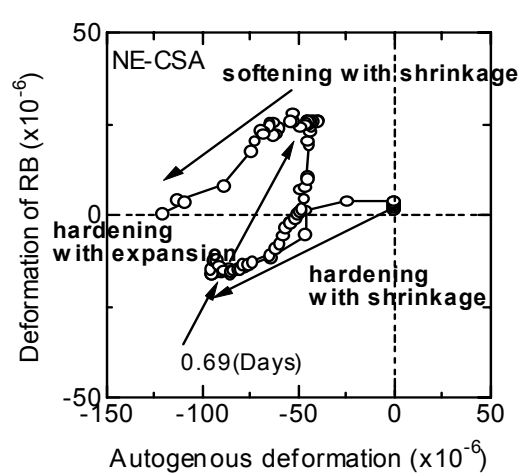

Fig. 17 Comparison of autogenous deformation of NE-CSA with deformation of reinforcing bar $(\mathrm{RB})$.

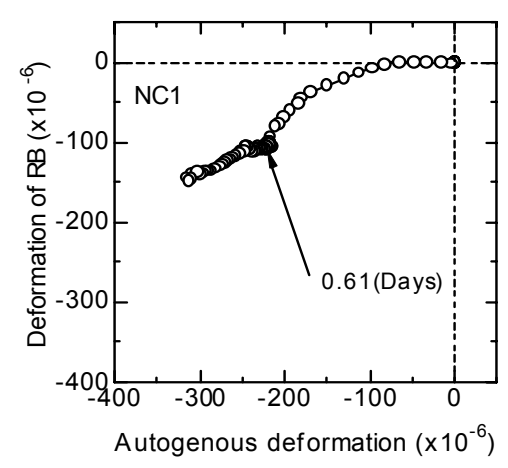

Fig. 18 Comparison of autogenous deformation of NC1 with deformation of reinforcing bar (RB).

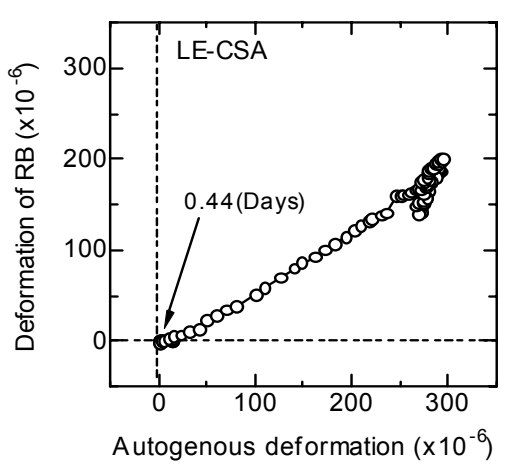

Fig. 19 Comparison of autogenous deformation of LE-CSA with deformation of reinforcing bar (RB). 


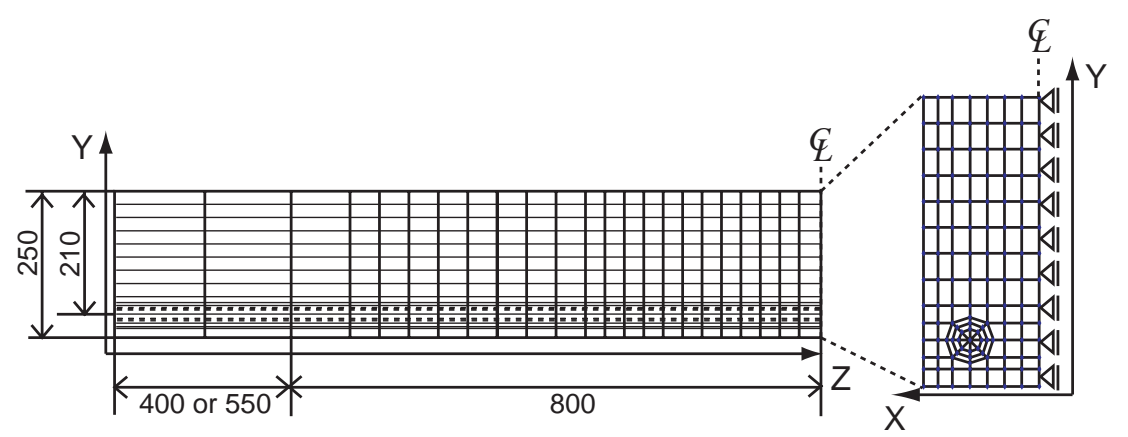

Fig. 20 Mesh of B1 and B2 beam specimen for FE analysis.

velopment of Young's modulus, history of temperature, and autogenous deformation, Poisson's ratio, Thermal coefficient, and creep coefficient behavior.

With regard to the history of autogenous deformation and temperature, analysis was carried out with experimental data. The creep model, which is shown in section 4.3 , is assumed to be applicable to the case of tensile creep.

The Poisson's ratio of concrete is assumed to be constant as a value of sealed concrete at 28 days, as shown in Table 5, and a value of 0.30 was adopted as the Poisson's ratio of the reinforcing bar. Values of the thermal coefficient are assumed to be constant as well. The value of $10.0 \times 10^{-6} /{ }^{\circ} \mathrm{C}$ for the concrete and the value of $11.8 \times 10^{-6} /{ }^{\circ} \mathrm{C}$ for the reinforcing bar were adopted.

Isoparametric elements with 8 nodes were adopted for the FE analysis, and 2792 elements and 3474 nodes were used for the beam specimens of the B1 and B2 series, which are shown in Fig. 20.

The S1 series use 2782 hexahedron elements with 153 line elements for stirrups and the S2 series use 3425 hexahedron elements with 240 line elements. The division of the mesh for the FE analysis takes into account the symmetry of the specimen. The hooks in the B1 series are ignored as the discussion will focus on the center part of the beam specimen and as the transfer length is considered to be sufficient (Takeuchi et al. 1997).

In the proposed FE analysis, non-cracking in early age is assumed, as this micro-cracking in early age is a recent matter of argument and the criteria of cracking in early age are still ambiguous. However, the possibility of cracking in the vicinity of reinforcing bars still remains. Regarding this aspect, the possibility of cracking and the effect of cracking on self-induced stress will be discussed indirectly through analysis results.

\subsection{Sensitivity of FE analysis to number of in- tervals}

Sensitivity of the applied analysis to the number of intervals may result in difficulty in evaluation of the proposed FE model. Hence, case studies of $\mathrm{NC} 1$ with different number of intervals, namely 17, 27, and 57 intervals, were executed. Fig. 21 shows the obtained results.
The incremental time intervals correspond to the constant incremental free deformations in each case. The resulting stress in the reinforcing bar with 17,27, and 57 intervals are $30.8 \mathrm{~N} / \mathrm{mm}^{2}, 30.6 \mathrm{~N} / \mathrm{mm}^{2}$, and $31.0 \mathrm{~N} / \mathrm{mm}^{2}$, respectively. It follows from these results that sensitivity to the number of intervals is minor for the proposed analysis and it may make less than a $1.5 \%$ difference in results under the condition of more than 17 intervals.

\subsection{Sensitivity of FE analysis to creep function}

In the proposed FE analysis, the creep coefficient model shown in Figs. 13 and $\mathbf{1 4}$ was adopted. These are the curves of ultimate creep coefficient and coefficient for the rate of creep development as a function of relative Young's modulus that are obtained without regard to cement type and additive type. However as it can be seen in Figs. 13 and 14, the data are spread around regression curves. Hence how these variations of data affect simulation results should be grasped.

In both Figs. 13 and 14, cover-all curves, namely "upper curve" and "lower curve", are shown. These curves lead to 4 types of creep coefficients, i.e., $\beta_{H}$ of upper and $\phi$ of upper (bUfU), $\beta_{H}$ of lower and $\phi$ of lower (bLfL), $\beta_{H}$ of upper and $\phi$ of lower (bUfL), and $\beta_{H}$ of lower and $\phi$ of upper (bLfU), which is represented in Fig. 22. Among results of the FE analysis with these creep coefficients, bUfL gives the maximum value of stress in the reinforcing bar at 28 days, 34.2 $\mathrm{N} / \mathrm{mm}^{2}$, and bLfU gives the minimum value of 30.7

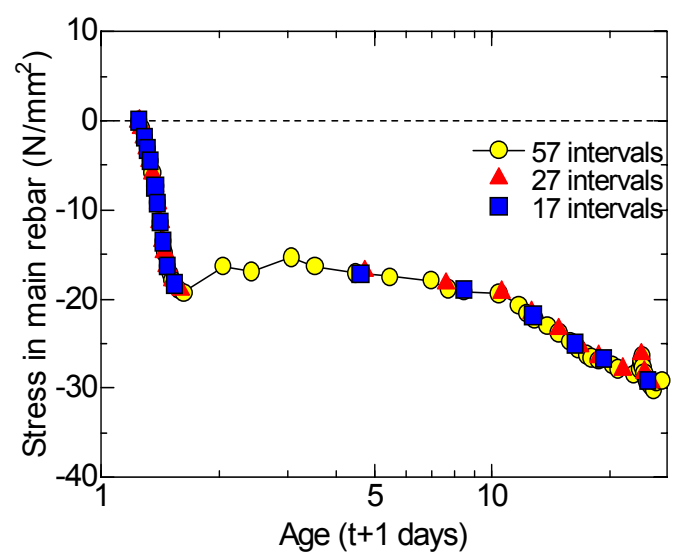

Fig. 21 Sensitivity of FE analysis by number of intervals. 


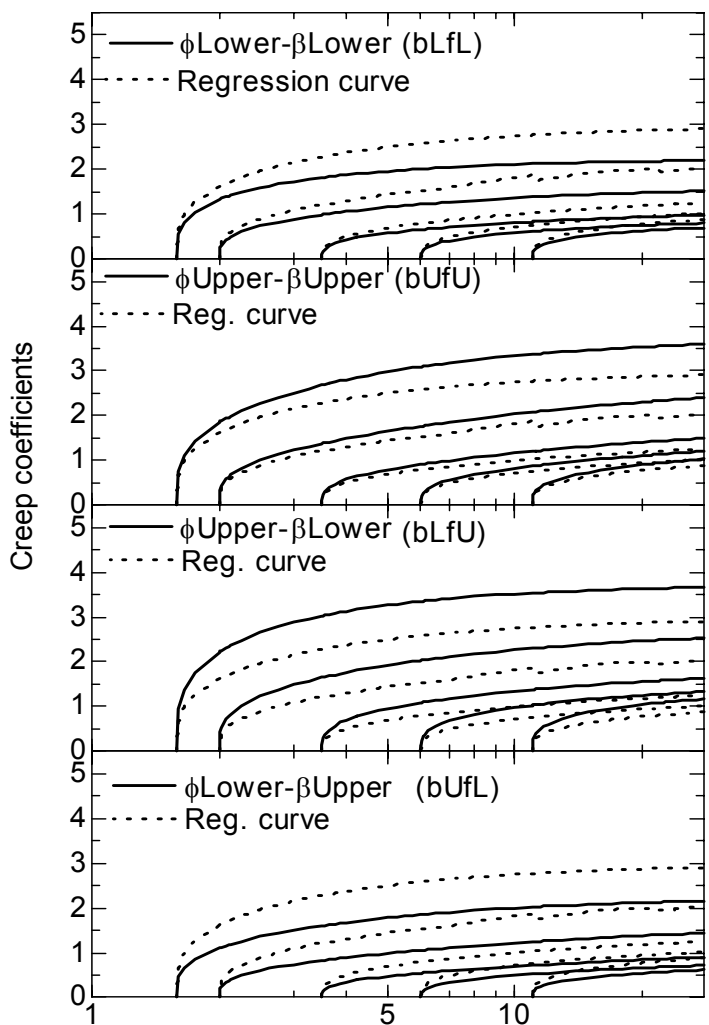

Temperature adjusted concrete age ( $\mathrm{t}+1$ days)

Fig. 22 Creep coefficients for sensitivity of FEM analysis.

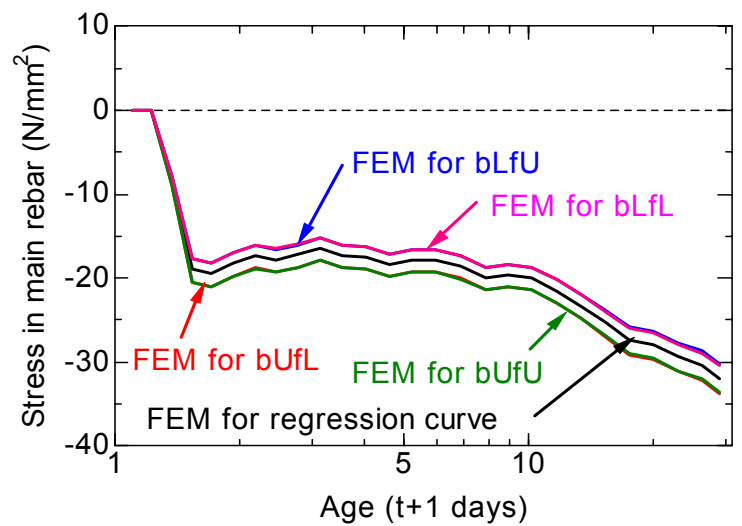

Fig. 23 Sensitivity of FE analysis with creep coefficients.

$\mathrm{N} / \mathrm{mm}^{2}$, while the FE analysis with the regression curve marks a value of $32.4 \mathrm{~N} / \mathrm{mm}^{2}$ (see Fig. 23). Accordingly, the variation of the creep coefficient in Figs. 13 and $\mathbf{1 4}$ has a small effect on the simulation and it results in a $\pm 5 \%$ difference. It is concluded that variation in the creep coefficient produces variation in simulation results within $\pm 5 \%$ on the condition that the concrete is high strength, which is characterized by a low water-to-binder ratio of less than 0.3 .

\subsection{Comparison of experimental results}

The experimental results of the beam specimens were evaluated with the proposed FE analysis and beam theory. Stress in reinforcing bars and stirrups, and concrete

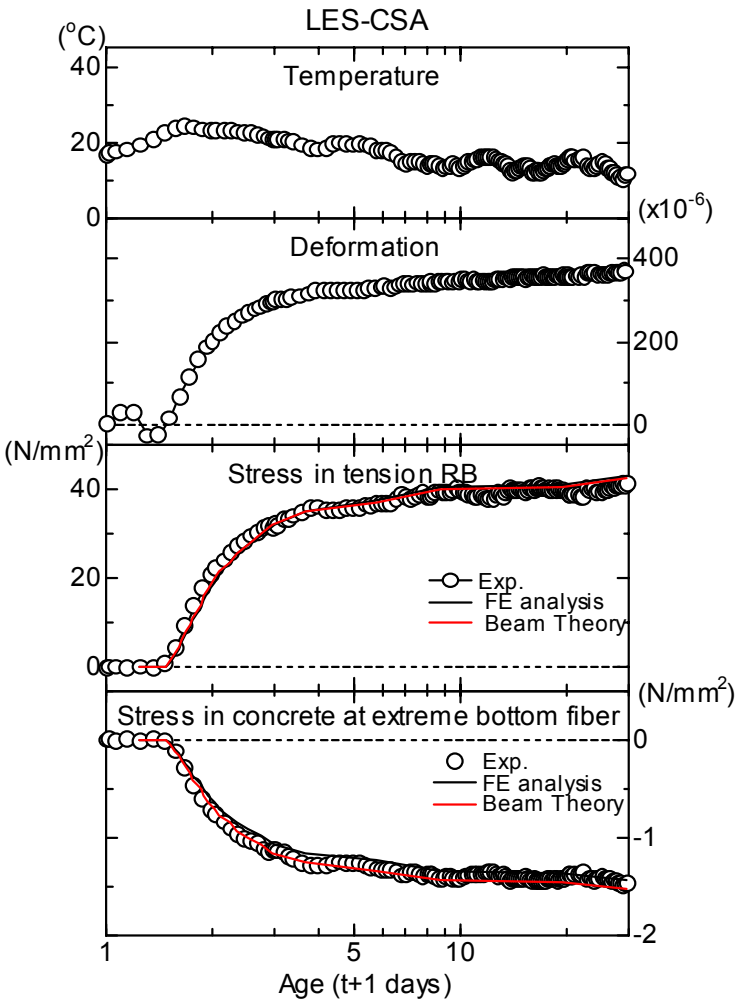

Fig. 24 Experimental results and simulation results of LES-CSA. Temperature in deformation specimen and beam specimen (Top), deformation of concrete (Second from the top), experimental stress in reinforcing bar (RB) compared with simulation result by FE analysis and proposed model by beam theory (Third from the top), stress of concrete at extreme bottom fiber compared with simulated result by $\mathrm{FE}$ analysis and Beam theory (Bottom).

at the extreme bottom fiber are presented with input data of temperature history as well as deformation history. The highest accuracy cases, LES-CSA and NC4, are shown in Figs. 24 and $\mathbf{2 5}$, respectively, and the worst accuracy case, NE-CSA, is presented in Fig. 26. The simulation results obtained with the proposed beam theory are plotted as well. In these analysis, the regression curves of Young's modulus underestimate experimental data during ages of 3 to 7 days. However, this is insignificant in the results of the FE analysis. For instance, in the case of NE-CSA, experimental Young's modulus leads to $0.6 \mathrm{~N} / \mathrm{mm}^{2}$ bigger tensile stress in $\mathrm{RB}$ at concrete age of 6 days.

Stress in the reinforcing bar by FE analysis is calculated by averaging $\mathrm{z}$-axis values at 8 nodes of each of the 4 elements centered in the reinforcing bar. The stress in the concrete at the extreme bottom fiber is the averaged values of 8 nodes of the element that is placed at the bottom in the $\mathrm{y}$ axis and the center in the $\mathrm{x}$ and $\mathrm{z}$ axes of the beam specimen. On the other hand, the stress in the concrete at the extreme bottom fiber by the beam theory is calculated based on the assumption of linear 


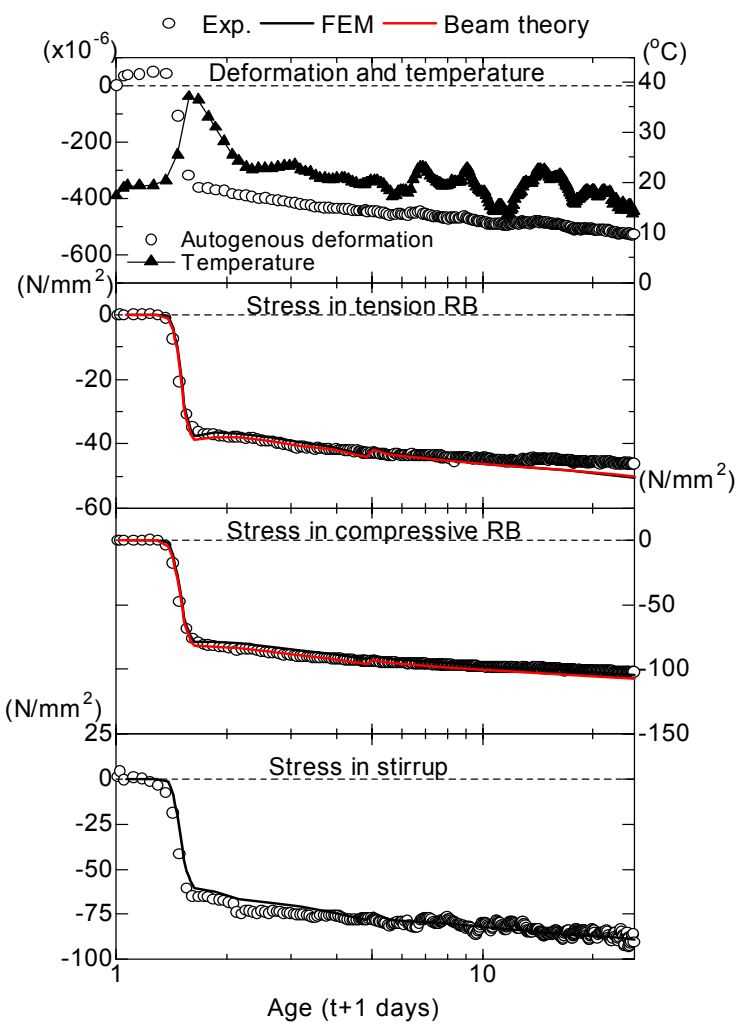

Fig. 25 Experimental results and simulation results of NC4. Temperature and deformation (Top), experimental stress in tensile reinforcing bar (RB) compared with simulation result by FE analysis (FEM) and proposed model by beam theory (Second from the top), stress of compressive reinforcing bar (Third from the top), and stirrup (Bottom).

strain distribution.

To evaluate the accuracy of the FE analysis, comparisons are plotted in Fig. 27 selecting three inflection points for each concrete that are observed at approximately 1,4 , and 28 days.

The FE analysis follows precisely the behavior of all the specimens, even the behavior of concrete strain from tensile stress to compressive stress, which cannot be simulated by the effective modulus method (Sato et al. 1999a). However, in a few cases, namely NES-CSA, NE-CSA, and NES-CSA-S2, the FE analysis results diverged from the experimental results after 10 days and a difference of approximately $5 \mathrm{~N} / \mathrm{mm}^{2}$ remained in the tensile reinforcing bar at 28 days. These three specimens exhibited similar behavior of deformation. The deformation of these specimens showed a sudden drop and the minimum value of the shrinkage strain was obtained at about 0.5 days followed by a slight expansion until 3 days. After the peak at 3 days, the specimen showed a second mild shrinkage behavior. This deformation behavior brings the steep increase of tensile stress in concrete at approximately 0.5 days followed by a gradual decrease. In this case, under the shrinkage process, cement particles with expansive additive are hydrating and

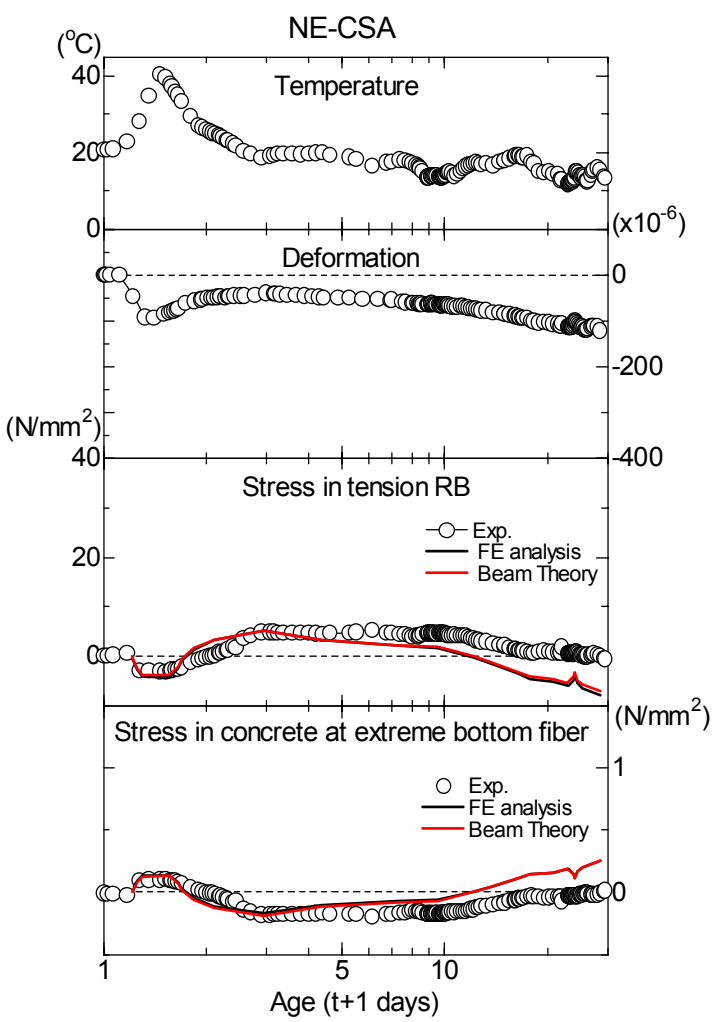

Fig. 26 Experimental results of NE-CSA. Temperature in deformation specimen and beam specimen (Top), deformation of concrete (Second from the top), experimental stress in tension rebar compared with simulation result by FE analysis and Beam theory (Third from the top), stress of concrete at tensional edge compared with simulated result by FEM and Beam theory (Bottom).

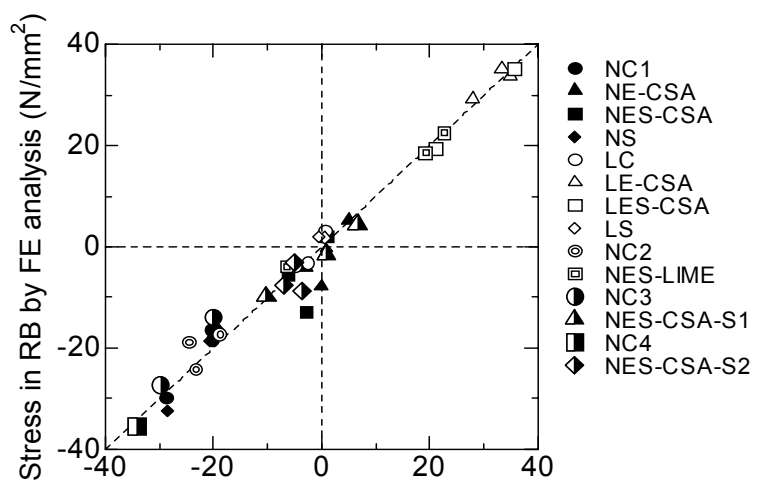

Experimental value of stress in $\mathrm{RB}\left(\mathrm{N} / \mathrm{mm}^{2}\right)$

Fig. 27 Comparison of FE analysis results with experiment with regard to stress in reinforcing bar (RB).

forming an optimum matrix in the vicinity of the reinforcing bar under shear stress. This compacted structure, however, may be injured by the E-CSA reaction and this may result in micro-cracks. In the expansion period, the injured matrix seems to be sound because the micro-cracks are unopened and bear compressive stress. On the other hand, in the shrinkage period, these mi- 
cro-cracks may lead to weak transmission of deformation under tensile stress field. This phenomenon does not apply to the case of concrete using E-CSA with low-heat Portland cement. In this case, the slow process of hydration may absorb the shock of reaction by E-CSA, resulting in a sounder matrix. The evidence for this explanation and micro-cracking remains a topic for

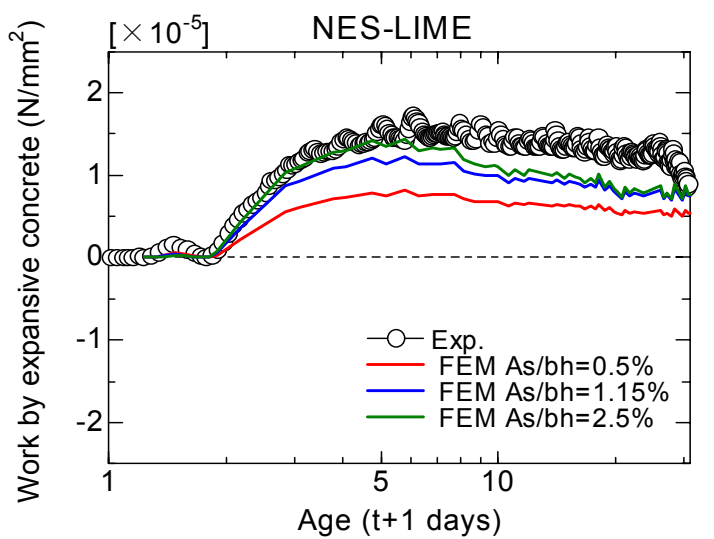

Fig. 28 Work by expansive concrete NES-LIME under different restraint condition.

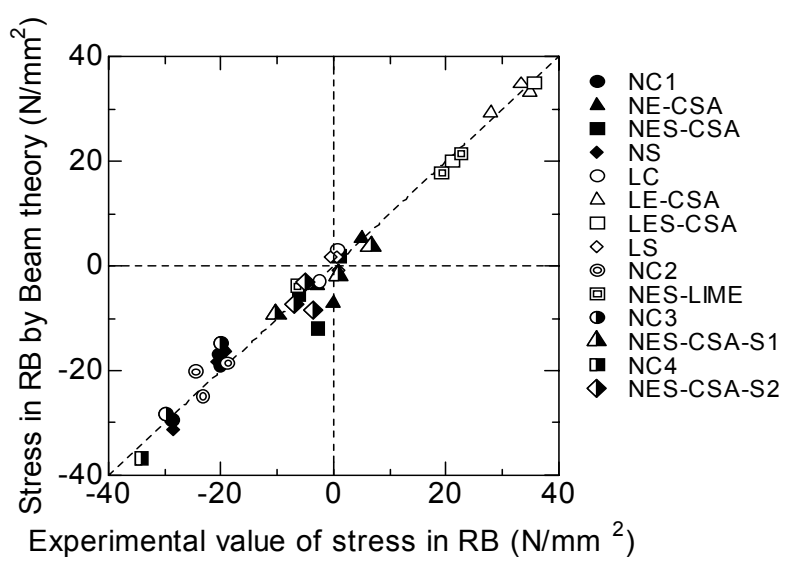

Fig. 29 Comparison of Beam theory results with experiment with regard to stress in reinforcing bar (RB).

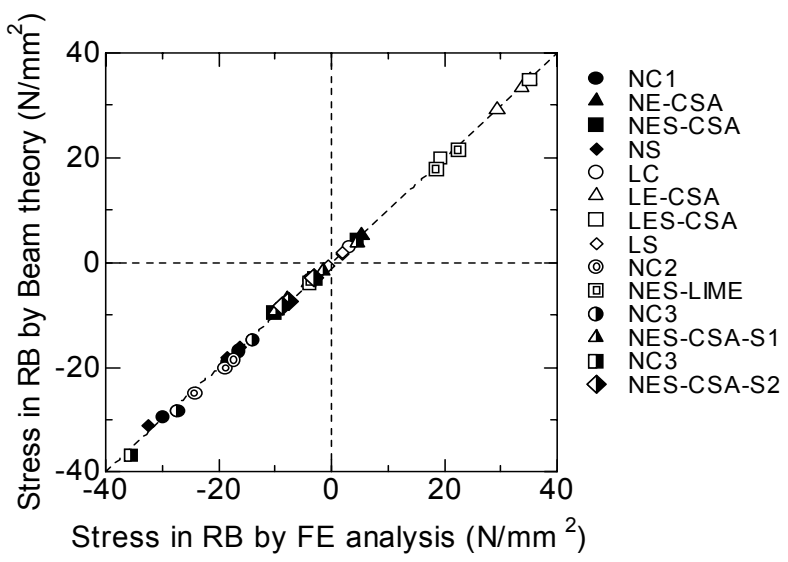

Fig. 30 Comparison of Beam theory results with experiment through stress in reinforcing bar (RB). future study.

The good agreement of experimental data with the FE analysis results indicates that concrete with expansive additive, which is considered to have non-linear properties in stress-strain relation on the normal strength level, has the same linear stress-strain relationship as that of normal concrete when it has a low water-to-binder ratio.

\subsection{Hypothesis of constant work of expansive concrete}

Tsuji suggested the hypothesis that a work stored in a unit volume of expansive concrete under restraint condition is constant at the final state in deformation behavior (Tsuji 1980). Applicability of this hypothesis is evaluated by $\mathrm{FE}$ analysis with reinforcement ratios of $2.5 \%, 1.15 \%$, and $0.5 \%$. In Fig. 28, results of work $U$ by NES-LIME for different reinforcement ratios are plotted and a disconformity of $U$ is noted. Thus, the linear stress-strain relationship does not coexist with the hypothesis of the constant work stored in a unit volume of expansive concrete when the expansive concrete is strengthened, although this hypothesis is confirmed under the uniaxial centering restraint condition and final state of deformation.

\subsection{Proposed beam theory}

In Fig. 29, comparisons of simulation results by the beam theory with experimental data are plotted for the same concrete ages as in Fig. 27. The accuracy of simulation is almost the same level as that obtained with the FE analysis.

Comparisons of simulation results obtained with the beam theory with results obtained with the FE analysis are plotted in Fig. 30. Fig. 30 shows a good agreement of the beam theory results with the FE analysis results even in the case of the S1 and S2 series that have stirrups. These results imply that the restraint condition normal to the longitudinal direction in beam is a somewhat minor problem from the viewpoint of engineering.

Hence it seems reasonable to conclude that the proposed practical model is quite useful for evaluating the stress in a beam with normal high-strength concrete as well as expansive concrete, and this beam theory is applicable to cases with stirrups that bring a three dimensional restraint condition to concrete.

\section{Conclusions}

1. It was confirmed experimentally that using low-heat Portland cement, shrinkage reducing agent, expansive additive, or a combination thereof, has an effect on reducing autogenous shrinkage, and that their compensation effect is independent and cumulative. It was also found that it is possible to create expansive high-strength concrete through the concomitant use of low-heat Portland cement and expansive additive, or through the use of lime type expansive additive in a low water-to-binder ratio.

2. The compensation for shrinkage, which is induced 
by using low-heat Portland cement, shrinkage reducing agent, expansive additive, or a combination thereof, reduces the tensile stress in beam specimens. Their effects on compensation of tensile stress are cumulative. NE-CSA and NES-CSA stored a small compressive stress in the beam specimen at 28 days, though they showed free deformation shrinkage at the same time. This fact indicates the importance of developing a model that takes into account the changing concrete properties with cement hydration, in order to evaluate the effect of materials on compensation for self-induced tensile stress.

3. Three-dimensional FE analysis based on the principle of superposition and a linear stress-strain relationship is proposed. This analysis evaluates the stress and the strain of concrete under restraint condition using models of Young's modulus, creep coefficient, history of autogenous deformation and temperature. The proposed FE analysis is able to precisely simulate the behavior of beams, even ones with expansive high-strength concrete, such as LE-CSA LES-CSA, NES-LIME.

4. The good agreement of the experimental data with the FE analysis results leads to the conclusion that concrete with expansive additive has the same linear stress-strain relationship as that of conventional high-strength concrete when it is strengthened by a low water-to-binder ratio. In a few cases, namely those of NE-CSA, NES-CSA, and NES-CSA-S2, the results of the FE analysis diverge from the experimental results. This does not occur in the cases of concrete using E-CSA with low-heat Portland cement. This fact implies that micro-cracking may occur at the vicinity of reinforcing bars. The mechanism of this behavior, including the experimental confirmation of micro-cracking, is a topic for further study.

5. From the case study, the linear stress-strain relationship of expansive concrete does not coexist with the hypothesis that the work stored in a unit volume by expansive concrete is constant when the expansive concrete has a low water-to-cement ratio.

6. As a practical calculation method, the beam theory, which is based on the same concept, is proposed as well. The proposed beam theory is useful for evaluating the stress in the beam with conventional high-strength concrete as well as expansive concrete, and this beam theory is applicable to cases with stirrups, which introduce a three-dimensional restraint condition to concrete.

7. From a mechanical point of view, it is possible to evaluate the stress and strain of conventional high-strength concrete as well as expansive high-strength concrete by the proposed methods, while further investigations for long-term durability are needed for the practical use of expansive high-strength concrete.

\section{Acknowledgements}

The authors express their sincere gratitude to $\mathrm{Mr}$. S.
Masaki, Mr. Y. Hiramatsu and the graduate students of Structural Materials Laboratories, Hiroshima University, who accomplished numerous experiments.

\section{References}

Bentur, A., Igarashi, S. and Kovler, K. (2001). "Prevention of autogenous shrinkage in high strength concrete by internal curing using wet lightweight aggregates." Cement and Concrete Research, 31, 1587-1591.

Bentz, D. P., Geiker, M. R. and Hansen, K. K. (2001). "Shrinkage-reducing admixtures and early-age desiccation in cement paste and mortars." Cement and Concrete Research, 31, 1075-1085.

Berke, N. S. and Li, L. (2003). "Effectiveness of shrinkage reducing admixtures in reducing total shrinkage." Advanced in Cement and Concrete, Copper Mountain, Colorado, USA, 101-109.

CEB, (1990). "CEB-FIP MODEL CODE 1990”, Thomas Telford, 2-29 - 2-34.

Chikamatsu, R., Takeda, N., Miura, N. and Sogo, S., (1997). "Study on lower shrinkage of high strength, high fluidity concrete." Proceedings of the Japan Concrete Institute, 19 (1), 169-174. (in Japanese)

Holt, E. E. and Leivo, M. T. (2000). "Methods of reducing early-age shrinkage." Proceedings of the International RILEM Workshop on Shrinkage of Concrete, Shrinkage 2000, Paris, France.

Hori, I., Morioka, M., Sakai, E. and Daimon, M. (1998). "Influence of expansive additives on autogenous shrinkage." International Workshop on Autogenous Shrinkage of Concrete, JCI, Edited by Tazawa, E., Hiroshima, Japan, E \& FN SPON, 187-194.

Hori, A., Andou, T., Otabe, Y. and Suzuki, Y. (2001). "Development of initial defect-free high-performance concrete." Concrete Journal, JCI, 39 (8), 16-21. (in Japanese)

JCI, (1999a). “Autogenous Shrinkage of Concrete." In: E. Tazawa, Ed. London: E \& FN SPON, 21-26.

JCI, (1999b). "Autogenous Shrinkage of Concrete." In: E. Tazawa, Ed. London: E \& FN SPON, 31.

Jensen, O. M. and Hansen, P. F. (2001). "Water-entrained cement-based materials: I. Principle and theoretical background", Cement and Concrete Research, 31, 647-654.

Jensen, O. M. and Hansen, P. F. (2002). "Water-entrained cement-based materials: II. Implementation and experimental results", Cement and Concrete Research, 32, 973-978.

JSA, (2001a). “JIS-A-1108”, JIS Handbook, 11, 610-612 (in Japanese)

JSA, (2001b). "JIS-A-1113", JIS Handbook, 11, 618-619 (in Japanese)

JSCE, (2002). "Standard Specification for Design and Construction of Concrete Structures." Japan Society of Civil Engineers.

Kameta, S., Sato, R. and Abe, Y. (2000). "Stresses at joint interface between existing continuously 
reinforced concrete pavement and overlay concrete with expansive additive and shrinkage reducing agent." 4th International Workshop on Design Theories and Their Verification of Concrete Slabs for Pavements and Rail Roads, 305-320.

Neville, A. M., Dilger, W. H. and Brooks, J. J. (1983). "Creep of Plain and Structural Concrete", Construction Press, 246-255.

Ogawa, A., Sakata, K. and Tanaka, S. (1995). "A study on reducing shrinkage of highly-flowable concrete." Second CANMET/ACI International Symposium on Advanced in Concrete Technology, Las Vegas, Nevada, USA, 55-72.

Paillere, A. M., Buil, M. and Serrano, J. J. (1989). "Effect of fiber addition on the autogenous shrinkage of silica fume concrete." ACI Materials Journal, 86(2), 139-144.

Sato, R., Masaki, S., Hiramatsu, Y. and Kodama, K. (2003). "Serviceability performance evaluation of reinforced high strength concrete beams." 2nd International Specialty Conference on the Conceptual Approach to Structural Design, Cl-Premier, Italy, 763-770.

Sato, R., Tanaka, S., Hayakawa, T. and Tanimura, M. (1999a). "Experimental studies on reduction of autogenous shrinkage and its induced stress in high strength concrete." Proceedings of the 2nd International Research Seminar on Self-Desiccation and Its Importance in Concrete Technology, Lund, Sweden, 163-171.

Sato, R., Xu, M. and Y, Yang. (1997). "Stresses of high-strength concrete due to autogenous shrinkage combined with hydration heat of cement." Third CANMET/ACI International Conference on High-Performance Concrete, Kuala Lumpur, Malaysia, SP 172-44, 837-852.

Sato, R., Tezuka, M. and Anzai, S. (1999b). "Deformation and crack width of prestressed reinforced high strength concrete members." 5th International Symposium on Utilization of High Strength/High Performance Concrete, Vol. 1, Sandefjord, Norway, 598-607.

Schrage, I., Mangold, M. and Sticha, J. (1992) "An approach to high-performance concrete in Germany." Fourth CANMET/ACI International Conference on Fly Ash, Silica Fume, Slag, and Natural Pozzolans in Concrete, Istanbul, Turkey, SUPPLEMENTARY PAPERS, 493-511.

Schwartzentruber, A., Philippe, M., Marchese, G. and Laurence, O. (2002). "Cracking tendency of UHSC Influence of fibers and expansive admixtures." 6th International Symposium on Utilization of High Strength/High Performance Concrete, Vol. 2, Leipzig, Germany, 1391-1405.

Takeuchi, M., Tanaka, S., Sato, R., and Suzuki, K. (1997) "Evaluation of the autogenous shrinkage of high strength concrete". Proceedings of the Japan Concrete Institute, 19 (1), 751-756.
Tanimura, M., Sato, R., Shimoyama, Y. and Omori, H. (2001a). "Improvement of flexural behavior of reinforced high strength concrete members by reducing autogenous shrinkage." Concrete Science and Engineering, 3 (11), 179-184.

Tanimura, M., Hiramatsu, Y., Hyodo, H. and Sato, R. (2002a). "Flexural performance of RC members made of low shrinkage-high strength concrete." 6th International Symposium on Utilization of High Strength/High Performance Concrete, Vol. 2, Leipzig, Germany, 1437-1452.

Tanimura, M., Hyodo, H., Sato, T. and Sato, R. (2000). "An investigation on reducing shrinkage of high strength concrete." Proceedings of the Japan Concrete Institute, 22 (2), 991-996. (in Japanese)

Tanimura, M., Hyodo, H., Omori, H. and Sato, R. (2001b). "Experimental study on reduction of shrinkage stress of high strength concrete." Proceedings of the Japan Concrete Institute, 23 (2), 1075-1080. (in Japanese)

Tanimura, M., Hyodo, H., Nakamura, H. and Sato, R. (2002b). "Effectiveness of expansive additive on reduction of autogenous shrinkage stress in high-strength concrete." Proceedings of the Third International Research Seminar on Self-Desiccation and Its Importance in Concrete Technology, Lund, Sweden, Lund, Sweden, 205-216.

Tazawa, E. and Miyazawa, S. (1992a). "Autogenous shrinkage of cement paste with condensed silica fume." Fourth CANMET/ACI International Conference on Fly Ash, Silica Fume, Slag, and Natural Pozzolans in Concrete, Istanbul, Turkey, Supplementary Papers, 875-894.

Tazawa, E., Matsuoka, S., Miyazawa, S. and Okamoto, S. (1994). "Effect of autogenous shrinkage on self stress in hardening concrete." International RILEM Symposium on Thermal Cracking in Concrete at Early Ages, 221-228.

Tazawa, E. and Miyazawa, S. (1995). "Influence of cement and admixture on autogenous shrinkage of cement paste." Cement and Concrete Research, 25 (2), 281-287.

Tazawa, E. and Miyazawa, S. (1992b). "Autogenous shrinkage caused by self desiccation in cementitious material." 9th International Congress on the Chemistry of Cement, Vol. 4, New Delhi, India, 712-718.

Tsuji, Y. (1980). "Method of estimating expansion strains produced in reinforced concrete members using expansive cement concrete." Cedric Willson Symposium on Expansive Cement, ACI SP 64-16, 311-319.

Tsutsui, H., Sato, R. and Xu, M. (1996). “A study on stress due to autogenous shrinkage in high-strength concrete." JCA Proceedings of Cement \& Concrete, 50, 478-483. (in Japanese)

Yang, Y., Sato, R. (2001). "Thermal expansion coefficient of HSC at early ages." Proceedings of 2001 Second 
International Conference on Engineering Materials, JSCE and CSCE, San Jose, USA, 133-142.

Weiss, W. J., Borichevsky, B. B. and Shah, S. P. (1999).

"The influence of a shrinkage reducing admixture on early-age shrinkage behavior of high performance concrete." 5th International Symposium on Utilization of High Strength/High Performance Concrete, Vol. 2, Sandefjord, Norway, 1339-1350. 